\title{
Fracture strength of zirconia implant abutments on narrow diameter implants with internal and external implant abutment connections: A study on the titanium resin base concept
}

Sailer, Irena ; Asgeirsson, Asgeir G ; Thoma, Daniel S ; Fehmer, Vincent ; Aspelund, Thor ; Özcan, Mutlu ; Pjetursson, Bjarni E

\begin{abstract}
BACKGROUND There is limited knowledge regarding the strength of zirconia abutments with internal and external implant abutment connections and zirconia abutments supported by a titanium resin base (Variobase, Straumann) for narrow diameter implants. OBJECTIVES To compare the fracture strength of narrow diameter abutments with different types of implant abutment connections after chewing simulation. MATERIAL AND METHODS Hundred and twenty identical customized abutments with different materials and implant abutment connections were fabricated for five groups: 1-piece zirconia abutment with internal connection (T1, Cares-abutment-Straumann BL-NC implant, Straumann Switzerland), 1-piece zirconia abutment with external hex connection (T2, Procera abutment-Branemark NP implant, Nobel Biocare, Sweden), 2-piece zirconia abutments with metallic insert for internal connection (T3, Procera abutment-Replace NP implant, Nobel Biocare), 2-piece zirconia abutment on titanium resin base (T4, LavaPlus abutment-VarioBase-Straumann BL-NC implant, 3M ESPE, Germany) and 1-piece titanium abutment with internal connection (C, Cares-abutment-Straumann BL-NC implant, Straumann, Switzerland). All implants had a narrow diameter ranging from 3.3 to $3.5 \mathrm{~mm}$. Sixty un-restored abutments and 60 abutments restored with glass-ceramic crowns were tested. Mean bending moments were compared using ANOVA with p-values adjusted for multiple comparisons using Tukey's procedure. RESULTS The mean bending moments were $521 \pm 33 \mathrm{Ncm}$ (T4), $404 \pm 36 \mathrm{Ncm}$ (C), $311 \pm 106 \mathrm{Ncm}$ (T1) $265 \pm$ $22 \mathrm{Ncm}$ (T3) and $225 \pm 29$ (T2) for un-restored abutments and $278 \pm 84 \mathrm{Ncm}$ (T4), $302 \pm 170 \mathrm{Ncm}$ (C), $190 \pm 55$ $\mathrm{Ncm}$ (T1) $80 \pm 102 \mathrm{Ncm}$ (T3) and $125 \pm 57$ (T2) for restored abutments. For un-restored abutments, C and T4 had similar mean bending moments, significantly higher than those of the three other groups $(\mathrm{p}<.05)$. Titanium abutments $(\mathrm{C})$ had significantly higher bending moments than identical zirconia abutments (T1) $(\mathrm{p}<.05)$. Zirconia abutments (T1) with internal connection had higher bending moments than zirconia abutments with external connection $(\mathrm{T} 2)(\mathrm{p}<.05)$. For all test groups, the bending moments were significantly reduced when restored with all-ceramic crowns. CONCLUSIONS For narrow diameter abutments, the fracture strength of 2-piece internal connected zirconia abutments fixed on titanium resin bases was similar to those obtained for 1-piece titanium abutments. Narrow diameter zirconia abutments with internal connection exhibited higher fracture strength than zirconia abutments with an external connection. Titanium abutments with an internal connection were significantly stronger than identical zirconia abutments.
\end{abstract}

DOI: https://doi.org/10.1111/clr.13139

Posted at the Zurich Open Repository and Archive, University of Zurich

ZORA URL: https://doi.org/10.5167/uzh-150981

Journal Article

Accepted Version 
Originally published at:

Sailer, Irena; Asgeirsson, Asgeir G; Thoma, Daniel S; Fehmer, Vincent; Aspelund, Thor; Özcan, Mutlu; Pjetursson, Bjarni E (2018). Fracture strength of zirconia implant abutments on narrow diameter implants with internal and external implant abutment connections: A study on the titanium resin base concept. Clinical Oral Implants Research, 29(4):411-423.

DOI: https://doi.org/10.1111/clr.13139 
Fracture strength of zirconia implant abutments on narrow diameter implants with internal and external implant abutment connections: A study on the titanium resin base concept

Irena Sailer ${ }^{1}$

Asgeir Asgeirsson ${ }^{2}$

Daniel S. Thoma

Vincent Fehmer ${ }^{1}$

Thor Aspelund ${ }^{3}$

Mutlu Özcan²*

Bjarni Pjetursson ${ }^{1,4^{*}}$

* Both authors contributed equally and share the last authorship

Authors'affiliations:

${ }^{1}$ Division of Fixed Prosthodontics and Biomaterials, University Clinic of Dental Medicine, University of Geneva, Switzerland

${ }^{2}$ Clinic of Fixed and Removable Prosthodontics and Dental Material Science, Center of Dental Medicine, University of Zurich, Switzerland,

${ }^{3}$ Public Health Sciences, University of Iceland, Reykjavik, Iceland

${ }^{4}$ Clinic for Reconstructive Dentistry, Faculty of Odontology, University of Iceland, Reykjavik, Iceland

Short title: Fracture resistance of zirconia implant abutments

\section{Corresponding author:}

Prof. Dr. Irena Sailer

Division of Fixed Prosthodontics and Biomaterials

University Clinics of Dental Medicine, University of Geneva

19, rue de Barthélemy- Menn

1205 Geneva, Switzerland

Tel: +41223794050

Fax: +41223794052 


\begin{abstract}
Background: There is limited knowledge regarding the strength of zirconia abutments with internal and external implant-abutment connections and zirconia abutments supported by a titanium resin base (Variobase, Straumann) for narrow diameter implants.
\end{abstract}

Objectives: To compare the fracture strength of narrow diameter abutments with different types of implant-abutment connections after chewing simulation.

Material and methods: Hundred and twenty identical customized abutments with different materials and implant-abutment connections were fabricated for five groups: 1-piece zirconia abutment with internal connection (T1, Cares-abutment-Straumann BL-NC implant, Straumann Switzerland), 1-piece zirconia-abutment with external hex connection (T2, Procera abutment-Branemark NP implant, Nobel Biocare, Sweden), 2-piece zirconia abutments with metallic insert for internal connection (T3, Procera abutment-Replace NP implant, Nobel Biocare) and 2-piece zirconia abutment on titanium-resin-base (T4, LavaPlus abutment-VarioBase-Straumann BL NC implant, 3M ESPE, Germany) and 1piece titanium abutment with internal connection $(C$, Cares abutment-Straumann BL-NC implant, Straumann, Switzerland). All implants had a narrow diameter ranging from 3.3 to $3.5 \mathrm{~mm}$. Sixty un-restored abutments and 60 abutments restored with glass-ceramic crowns were tested. Mean bending moments were compared using Anova with p-values adjusted for multiple comparisons using Tukey's procedure.

Results: The mean bending moments were $521 \pm 33$ Ncm (T4), 404 \pm 36 Ncm (C), $311 \pm 106$ Ncm (T1) $265 \pm 22 \mathrm{Ncm}$ (T3) and 225 \pm 29 (T2) for un-restored abutments, and $278 \pm 84 \mathrm{Ncm}$

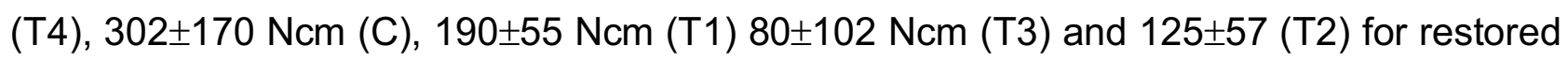
abutments. For un-restored abutments, C and T4 had similar mean bending moments, significantly higher than those of the 3 other groups $(p<0.05)$. Titanium abutments $(C)$ had 
significantly higher bending moments than identical zirconia abutments (T1) $(p<0.05)$. Zirconia abutments (T1) with internal connection had higher bending moments than zirconia abutments with external connection (T2) $(\mathrm{p}<0.05)$. For all test groups the bending moments were significantly reduced when restored with all-ceramic crowns.

Conclusions: For narrow diameter abutments, the fracture strength of 2-piece internal connected zirconia abutments fixed on titanium resin bases was similar to those obtained for 1-piece titanium abutments. Narrow diameter zirconia abutments with internal connection exhibited higher fracture strength than zirconia abutments with an external connection. Titanium abutments with an internal connection were significantly stronger than identical zirconia abutments.

Key words: Aging, Bending moment, Hybrid abutment, Implant abutment, Implantabutment connection, Titanium resin base, Zirconia abutment 


\section{Introduction}

Customized ceramic implant abutments are frequently used as part of implant-borne reconstructions predominantly in esthetically demanding clinical situations. The main benefit of ceramic abutments is based on esthetics demonstrating less discoloration of the peri-implant mucosa compared to titanium abutments (Jung et al. 2008). The first ceramic abutments introduced for esthetic indications were made out of high-strength ceramic alumina (Prestipino \& Ingber 1993a; Prestipino \& Ingber 1993b). Alumina abutments, however, exhibited fractures during clinical function resulting in a cumulative survival rate of only 93\% at 1 year of clinical service (Andersson et al. 1995; Andersson et al. 2001).

Abutments made out of high-strength ceramic zirconia exhibited superior fracture resistance compared to alumina abutments (Att et al. 2006; Glauser et al. 2004; McGlumphy et al. 1992; Yildirim et al. 2003). The clinical long-term stability of zirconia abutments was reported to be excellent and similar to titanium abutments (Glauser et al. 2004; Sailer et al. 2009a; Zembic et al. 2013). Due to these favorable clinical results, zirconia abutments are available for almost all implant systems, thereby fulfilling the rising demand for esthetic implant-borne reconstructions. More recently, dyed fluorescent zirconia was introduced to further improve the esthetic soft tissue outcome of implant-borne reconstructions. In a recent study it was demonstrated that shading of the white zirconia with a fluorescent dye could lead to allceramic abutments that mimic the optical properties of natural teeth (Happe et al. 2013).

The various implant systems available today offer different types of implant-abutment connections. Depending on the design of the respective implants, the implant-abutment connection is characterized by being internal or external. For zirconia abutments, an internal connection can be accomplished by the abutment itself (one-piece), or by a secondary metallic coupling/component (two-piece). Several studies demonstrated that the type of 
connection has a significant influence on the stability of titanium abutments. Higher stability was found at internally connected titanium abutments compared to externally connected ones (Khraisat et al. 2002; Mollersten et al. 1997; Norton 1997). Moreover, the type of connection had an important influence on the stability of zirconia abutments. Significantly higher stability was found for two-piece internally connected zirconia abutments than for one-piece internally or externally connected zirconia abutments (Sailer et al. 2009a; Sailer et al. 2009b).

The available laboratory and clinical studies solely tested regular diameter zirconia abutments connected to regular diameter implants. This type of implant/abutment diameter has most frequently been used in the esthetic areas (i.e. the central incisor and premolar regions). Due to the limited stability, narrow diameter implants were mostly indicated in regions where less load was expected such as the maxillary lateral incisor or the mandibular incisor regions.

New narrow-diameter implants made of a high strength zirconium-titanium were evaluated in a number of preclinical and clinical studies (loannidis et al. 2015; Thoma et al. 2011). These alloys allow increasing the clinical indications for narrow diameter implants for the central incisor and premolar regions as well as for multi-unit reconstructions (Moraguez et al. 2016). Possible advantages of narrow diameter implants as opposed to regular diameter implants include a less invasive surgery, predominantly in anatomical areas with an insufficient bone width. This leads to less GBR (guided bone regeneration), faster healing, earlier loading and cost reduction for the patient. Most likely, these narrow implants will also be used in combination with zirconia abutments in the esthetic zone in the future. One has to bear in mind, however, that reducing the diameter could lead to a critical decline of the zirconia abutment dimensions, possibly decreasing the stability of ceramic abutments. No 
information is yet available on the stability of narrow diameter zirconia abutments connected to the implants with the above-mentioned types of implant-abutment connections.

Therefore, the aim of this study was to evaluate the fracture strength and bending moments of different types of zirconia implant abutments on narrow diameter implants with internal and external implant abutment connections, and to compare it to the one of an internally connected narrow diameter titanium abutment. The null-hypotheses of this study were that a) narrow diameter zirconia abutments supported by titanium resin bases exhibit the same fracture strength as narrow diameter titanium abutments, b) the type of connection (internal vs. external) does not influence the fracture strength, and c) the type of abutment material (zirconia vs. titanium) does not influence the fracture strength of the abutments.

\section{Materials and methods}

In this in vitro study, the fracture load of 4 types of customized zirconia test abutments, and one type of customized titanium abutment (control) were included. The present study protocol strictly followed the procedures of 4 previous studies (Leutert et al. 2012; Muhlemann et al. 2014; Sailer et al. 2009b; Truninger et al. 2012) in order to provide standardization and comparability of data.

Test-group 1 (T1): 1-piece zirconia abutment with internal implant abutment connection (Cares abutments on Bonelevel NC Roxolid implants, Straumann, Basel, Switzerland).

Test-group 2 (T2): 1-piece zirconia abutment with external implant abutment connection (Procera abutments on Brånemark MK III NP implants, Nobel Biocare, Gothenburg, Sweden). 
Test-group 3 (T3): 2-piece zirconia abutment with internal implant abutment connection provided by a corresponding secondary metallic coupling (Procera abutments on Replace Select straight NP, Nobel Biocare, Gothenburg, Sweden).

Test-group 4 (T4): 2-piece fluorescent zirconia abutment with internal implant abutment connection (Lava Plus zirconia abutments (ESPE, Germany), supported by a titanium resin base (Variobase, Straumann) on Bonelevel NC Roxolid implants, Straumann, Basel, Switzerland).

Control-group (C): 1-piece titanium abutments with internal implant abutment connection (CARES abutments on Bonelevel NC Roxolid implants, Straumann, Basel, Switzerland).

In each group, 24 identical abutments were fabricated. The same design of the abutment was used as in the previous investigations, following the clinical situation of one patient. For details on the abutment shape and design please see: (Leutert et al. 2012; Muhlemann et al. 2014; Sailer et al. 2009b; Truninger et al. 2012). In each group 12 abutments were tested without a reconstruction. For the remaining 12 abutments identical leucit-reinforced glassceramic crowns (IPS Empress CAD, Ivoclar Vivadent, Schaan, Liechtenstein) were fabricated and cemented with resin cement (Rely X Unicem, 3M ESPE, Seefeld, Germany) before ageing and the fracture load test.

\section{Fabrication of the abutments}

The procedures in this study were performed according to the standardized test method used in a series of previous studies (Leutert et al. 2012; Muhlemann et al. 2014; Sailer et al. 2009b; Truninger et al. 2012). In these studies one clinical case with a single implant (Standard Plus, RN, Straumann) in the maxillary central incisor region was chosen for the fabrication of a customized "master abutment" (Cares, Straumann) (Sailer et al. 2009b) The shape of this "master-abutment" was virtually designed for the regular platform implant 
(Standard Plus RN, Straumann), following the anatomical requirements of the respective patient/site (Sailer et al. 2009b; Truninger et al. 2012). This "master abutment" shape was then transferred to the other tested implant-abutment systems (Sailer et al. 2009a; Sailer et al. 2009b).

The same "master abutment" was used in the present investigation for the fabrication of the different abutment types for narrow platform implant abutment connections. For this, the original STL data of the "master abutment" was virtually transferred from the regular platform onto a narrow platform (Cares, Straumann). The dimension of the implant-abutment connection were changed to narrow platform, however, no modification of the outer shape/ dimensions of the "master abutment" was performed (Figure 1).

This new "master abutment" data was used for the fabrication of the abutments in the test group $1(n=24)$ and the control group $(n=24)$ (Cares, Straumann).

For the fabrication of the abutments in test groups 2 and 3 , one abutment of test group 1 was scanned with a CAD/CAM scanner (Procera, Nobel Biocare, Sweden), and used for the fabrication of the 48 identical zirconia abutments (Procera).

The abutments in test group 4 were fabricated according to the procedures in test groups 2 and 3, yet using a different type of CAD/CAM system (Lava, ESPE, Seefeld, Germany). The "master abutment" was scanned (Lava ${ }^{\mathrm{TM}}$ Chairside Oral Scanner C.O.S., 3M ESPE) and 24 identical zirconia abutment copies were fabricated (ESPE, Germany). The abutments were adhesively cemented (Rely X Unicem, ESPE) to titanium resin bases (= hybrid abutment; titanium base with an extraorally cemented zirconia reconstruction, results in a reconstruction that can be screw-retained) (Variobase, Straumann), in order to establish the internal connection to the implants in this test group (Straumann Bonelevel NC Roxolid).

\section{Fabrication of the glass-ceramic crowns}


For the fabrication of the crowns, the original master cast of the previous investigations

(Sailer et al. 2009b) was modified by exchanging the regular platform implant replica to a narrow platform implant replica (NC implant analog, Straumann) in the same position.

The "master abutment" was fixed on the implant replica and the master cast was scanned with a CAD/CAM scanner (Cerec InEos, Sirona, Bensheim, Germany). The missing central incisor crown was designed virtually (Cerec 3D software, Sirona) representing the ideal shape for the respective clinical case.

Sixty identical glass-ceramic crowns were then milled out of the glass-ceramic blanks (IPS Empress CAD, Ivoclar Vivadent, Schaan, Liechtenstein), using the milling machine of the corresponding CAD/CAM system (Cerec InLab, Sirona).

After the milling, all crowns were adapted to the respective abutments in the different groups, and were glazed (e.max Ceram Glaze Powder, Ivoclar Vivadent) in a ceramic furnace (Austromat 4D, Dekema, Freilassing, Germany) following the manufacturer's instructions.

\section{Preparation of specimens}

All abutments were mounted to their corresponding implants and fixed with torque values recommended by the manufacturers. The abutment-screw access holes were then closed with a foam pellet (Pele Tim, VOCO GmbH, Cuxhaven, Germany) and a resin-based composite filling material (Tetric Classic, Ivoclar Vivadent AG, Schaan, Liechtenstein). The specimens were embedded following the recommendations of the ISO-Norm 14801 ("Dentistry-Implants-Dynamic fatigue test for endosseous dental implants", International Organization for Standardization 2007, Geneva, Switzerland).

The specimens were placed in custom-made acrylic resin holders with a $3 \mathrm{~mm}$ vertical distance from the implant shoulder to the top of the acrylic holder in order to simulate vertical 
bone loss (Figure 2) (ISO 14801). The specimens were fixed to the holders with flowable acrylic resin (ScandiQuick, ScanDia, Hagen, Germany) that was applied through a lateral drill hole with a syringe. The resin excess was carefully removed from the top of the acrylic resin holders.

In the groups restored with glass-ceramic crowns the abutments were cleaned with ethanol (95\%) and pre-treated with the corresponding silanes/primers (zirconia abutments: Rely-X Primer (3M ESPE); titanium abutments with: Alloy Primer (Kuraray). The glassceramic crowns were cleaned with ethanol (95\%), etched with a hydrofluoric acid (VITA Ceramics Etch, Vita Zahnfabrik, Bad Säckingen, Germany) and silanized (Rely-X Ceramic Primer, 3M ESPE).

Finally, the crowns were adhesively cemented on the abutments with self-adhesive resin cement (Rely-X Unicem, 3M ESPE) according to the manufacturer's recommendations.

\section{Artificial ageing}

The restored and un-restored specimens were subjected to thermo cycling $\left(5^{\circ}\right.$ to $50^{\circ} \mathrm{C}$, dwelling time 120s) and chewing simulation (1,200,000 cycles, $49 \mathrm{~N}, 1.67 \mathrm{~Hz}$, custom-made computer-controlled masticator, University of Zurich, Switzerland).

A corrosion-free indenter (ST V4A) with a rounded tip (ø: 8mm) was used as an antagonist material. The specimens were loaded $3 \mathrm{~mm}$ below the incisal edge at a $30^{\circ}$ angle of the indenter to the palatal surface of the crowns/ abutments. The vertical indenter movement for each chewing act was $2 \mathrm{~mm}$.

After chewing simulation all specimens were visually inspected for failures before testing.

\section{Fracture load test}


Following ageing, the fracture load $(\mathrm{N})$ of the specimens was measured using a Universal Testing Machine (Zwick/Roell Z010, Zwick, Ulm Germany, 1mm/min).

The load from the indenter (ISO Norm 14801: 2007) was applied at a $30^{\circ}$ angle to the palatal surfaces of the crowns/abutments. In order to ensure even force distribution to the crown/abutment during loading, a $0.5 \mathrm{~mm}$ thick tin foil (Dentaurum, Ispringen, Germany) was placed in between the specimens and the indenter (Kellerhoff \& Fischer 2007; Sailer et al. 2009b).

Static load was applied to the specimens until failure (Figure 3). Failure was defined either as visible fracture of the abutment/crown, or after a $20 \%$ decrease of the maximum load (F max) in case no obvious fracture was observed. For each group, the fracture load was recorded using the corresponding software (TestXpert V.II.02, Zwick/Roell, Ulm, Germany).

For comparison of the groups, the bending moments $(\mathrm{M})$ were calculated in $\mathrm{Ncm}$ according to the formula $M=0.5 \times F \times I(I S O$ Norm 14801,2007$)$, where $F$ was the load $(N)$ and I, the vertical distance from the simulated bone level to the center of load (cm) (Figure 2).

\section{Failure analysis}

All specimens were analyzed in digital microscope in order to locate and determine the origin of abutment/crown failure.

The abutment failures were classified as follows:

1. Catastrophic failure of abutment and/or crown due to fracture (partial, complete) with or without plastic deformation

2. Visible crack line on abutment and/or crown with or without plastic deformation

3. Plastic deformation of components (i.e. implant, abutment, screw) without fracture. 
In order to visualize the characteristics of the abutment/crown failures after loading, specimens of each group were embedded and sectioned with a diamond saw through the center of the sample in the bucco-oral direction (Well Diamond Wire Saws, Inc., Norcross, GA, USA). The embedded cross- sections were then observed under the microscope (Wild Heerbrugg, Heerbrugg, Switzerland) for further analysis of failure origin (figure 4a-h).

\section{Statistical analysis}

The initial distortion, the maximum fracture force, the minimum, maximum and mean bending moments and reason for failure for restored and un-restored abutments were reported using descriptive statistics, either means and standard deviations or counts. The mean bending moments were presented with box plots and compared using Anova with pvalues adjusted for multiple comparisons using Tukey's procedure. Comparisons between restored and un-restored abutments were done using unpaired t-tests. All analysis were performed using Stata, version 14.0 (Stata Corp., College Station, TX, USA). The level of statistical significance was set at $p<0.05$.

\section{Results}

The maximum fracture force ranged from $362 \pm 47 \mathrm{~N}$ to $883 \pm 56 \mathrm{~N}$ for un-restored abutments and from $86 \pm 109 \mathrm{~N}$ to $321 \pm 181 \mathrm{~N}$ for abutments restored with leucit-reinforced glass-ceramic crowns (Tables $1 \& 3$ ).

\section{Bending moments of un-restored abutments}

None of the abutments experienced fractures or loosening during the ageing process. The mean bending moment of the un-restored abutments ranged from $225 \pm 29$ Ncm to $521 \pm$ $33 \mathrm{Ncm}$ (Table 1). 
The highest mean bending moment was obtained by the group of internally connected 2piece abutments including a titanium resin base (T4) and the lowest mean bending moment by the 1-piece zirconia abutment with external hex connection (T2).

The control group (C) with 1-piece titanium abutment showed a mean bending moment of $404 \pm 36 \mathrm{Ncm}$, which was significantly higher than those of Test groups 1, 2 and $3(p<0.05)$. The fluorescent zirconia abutments supported by titanium resin bases (T4) had a mean bending moment of $521 \pm 33 \mathrm{Ncm}$, which was even higher than for the one of the control group $(C)(p<0.05)($ Tables $1 \& 2)$.

Zirconia abutments with internal connection (T1) showed significantly higher mean bending moment values $(311 \pm 108 \mathrm{Ncm})$ than zirconia abutments with external connection (T2) $(225 \pm 29 \mathrm{Ncm})(p<0.05)($ Tables $1 \& 2)$.

The largest range between the minimum and the maximum bending moment was in group T1 with minimum and maximum bending moment of $206 \mathrm{Ncm}$ and $492 \mathrm{Ncm}$, respectively. For all the others groups, minimum and maximum values ranged between $84 \mathrm{Ncm}$ and 116 $\mathrm{Ncm}$ (Table 1). In T1, all abutments had internal fractures after the bending moment test and in T2 all abutments presented external fractures. In T3, all the abutments fractured around the titanium connection and in T4 none of the abutments fractured but all the abutments showed deformation. In group C, all 12 abutments showed abutment deformation (Table 1).

\section{Bending moments of abutments restored with glass-ceramic crowns}

During the ageing process, 6 out of 12 crowns in the T3 group and two of the crowns in groups C and T2 each cracked but remained as a whole (Table 3). All samples underwent 
the fracture strength test.

The mean bending moments of the restored abutments ranged from $80 \pm 102 \mathrm{Ncm}$ to 302 $\pm 170 \mathrm{Ncm}$ (Table 3). The highest mean bending moment values were reported for group $\mathrm{C}$ followed by group T4 (278 $\pm 84 \mathrm{Ncm})$ and group T1 (202 $\pm 59 \mathrm{Ncm})$. The other groups, T2 $(133 \pm 61 \mathrm{Ncm})$ and T3 $(80 \pm 102 \mathrm{Ncm})$ exhibited significantly lower mean bending moment values than the control group (C) $(p<0.05 \& p<p<0.05)$ (Tables $3 \& 4)$.

Furthermore, group T3 showed significantly lower mean bending moments ( $80 \pm 102 \mathrm{Ncm})$ than group T4 $(278 \pm 84 \mathrm{Ncm})(\mathrm{p}<0.05)$ (Tables $3 \& 4)$.

Group C and T1 had abutments with the same configuration, but were made of different materials. When restored with glass-ceramic crowns, group $\mathrm{C}$ with titanium abutments showed a mean bending moment value of $302 \pm 170 \mathrm{Ncm}$ compared to mean bending moment values of $190 \pm 55 \mathrm{Ncm}$ for zirconia abutments $(p=0.09)$. Comparing restored zirconia abutments with internal and external connections, group T1 had mean bending moment values of $190 \pm 55 \mathrm{Ncm}$ compared with mean bending moment values of $125 \pm 57$ Ncm for group T2 $(p=0.56)$ (Tables $3 \& 4)$.

There was a major difference for the incidence of fractures of the leucit-reinforced glass ceramic crowns between the groups. In group T1, both, the crown and the abutment, had fractured in most cases, whereas in group T2, 10 crowns and 3 abutments fractured. In group T3, most of the crowns and two abutments fractured. In group T4, five crowns and 1 abutment fractured, and deformation was visible for 9 abutments. In group C, six crowns fractured and abutment deformations were visible for the remaining six abutments (Table 3).

\section{Comparison of un-restored and restored abutments}


All groups reported higher mean bending moment values for un-restored abutments compared to the restored abutments. This difference ranged from $99 \mathrm{Ncm}$ to $244 \mathrm{Ncm}$ and reached statistical significance for all groups. The largest difference was obtained between the two 2-piece zirconia abutment groups (T3 \& T4) (Table 5).

\section{Failure analysis}

The failure types from the microscope analysis are addressed in table 1 for unrestored abutments and table 3 for restored abutments. For test group 1 unrestored abutments, all abutments fractured in the internal part at the thinnest part of the abutment as can been seen in figure $4 \mathrm{a}$ and $4 \mathrm{~b}$. Within test group 1 all of the specimen underwent a deformation of the abutment screw. All of the abutments in test groups 2 and 3 (figure 4c, 4d) had an external fracture and an abutment screw loosening. Test group 2 didn't go in a microscope analysis because all of the abutments had a catastrophic failure which were detectable by the eye. Inner metallic part in test group 3 also had a deformtion. Test group 4 (figure 4e, 4f) and control group (figure $4 \mathrm{~g}, 4 \mathrm{~h}$ ) had no visible cracks nor fractures but all of them had a deformation in the internal part.

For the restored group 1 all of the abutments fractured externally at the screw neck at the abutment's thinnest part. In test groups 2 and 3 most of the abutments were intact due to a crown fracture. The few abutments that fractured had an external fracture. Most of the abutments in test group 4 had a deformation. In control group, half of the abutments had a deformation and the other half had a crown fracture. 


\section{Discussion}

In the present study, un-restored zirconia abutments connected internally to narrow diameter implants by means of a titanium resin base were significantly more stable than all other tested one- or two-piece zirconia abutments. In addition, the un-restored zirconia abutments supported by a titanium resin base exhibited a similar or even higher fracture strength than one-piece internally connected titanium abutments. Similar to previous experiments, the same configuration of un-restored one-piece internally connected abutments exhibited significantly more strength when made out of titanium than out of zirconia.

It has previously been reported that metallic secondary couplings increased the strength of zirconia abutments at internal implant-abutment connections (Sailer et al. 2009b). This observation was documented for regular diameter implant-abutment connections (Sailer et al. 2009b). In the present study on narrow diameter implant-abutment connections the metallic secondary coupling did not necessarily increase the strength of the zirconia abutments as demonstrated by group T3. However, the metallic internal connection given by the titanium resin base led to such a high stability of the zirconia abutments that it reached similar or even higher values compared to the titanium control abutments. Moreover, when restored with glass-ceramic crowns the strength of the zirconia abutments supported by titanium resin base was similar to the strength of control titanium abutments and significantly better than at 2 out of the 3 tested zirconia abutment types. In addition, debonding of a zirconia abutment from a titanium resin base never occurred in the present study, despite the aging process simulating 5 years of clinical function. This outcome is fairly positive since the fixation of the abutments/crowns to the titanium resin bases and the respective implants is solely accomplished by means of adhesive cementation. 
All previously published studies revealed that, in general, zirconia abutments exhibited approximately half the fracture strength compared to titanium abutments (Sailer et al. 2009a). In the present study on narrow diameter abutments this finding was less pronounced with control titanium abutments exhibiting approximately $30 \%-40 \%$ more strength as the conventional zirconia abutments (one-piece zirconia abutment). Due to the reduced strength of conventional zirconia abutments, the respective clinical indications were limited to sites with low masticatory forces such as the anterior regions of the maxilla and mandible. Limited scientific evidence exists on zirconia abutments being used in the posterior regions (Zembic et al. 2013). Few initial studies demonstrated that one-piece externally connected zirconia abutments showed favorable clinical results (Zembic et al. 2013).--These results were later confirmed in a systematic review (Jung et al. 2012), demonstrating that based on the available clinical evidence, all-ceramic crowns on ceramic abutments show similar survival rates as metal-based reconstructions.

One might speculate that based on the favorable outcomes of this in vitro study, the combination with a titanium resin base provides sufficient strength to expand the use of zirconia abutment to sites that were not recommended in the past. Clinical studies are needed to support this assumption in the future.

In the present study, the un-restored abutments exhibited higher bending moments than the restored abutments. This, however, did not affect the different abutment configuration and material in the same magnitude. Similar observations were made in an earlier study (Muhlemann et al. 2014). A possible reason for this could be the length of the implant restorative complex that might have led to more strain at the level of the implant abutment connection in the samples with the crowns as compared to the shorter un-restored abutments. Early failure experienced in the reconstruction material could not exert principle 
forces at the abutment level.

After chewing simulation of the restored abutments, some of the crowns presented small cracks that could be attributed to the sharp edges of abutment, possible crack formation during milling procedures or expansion of the resin cement used. These possible factors yielded to lower fracture load values resulting in lower bending moment. In addition, leucite glass ceramics were used as crown materials. This material has inferior mechanical properties than many other ceramics and could therefore resulted in lower bending moment. This type of ceramics was chosen, however, to have the same material as was used in the previous investigations, (Leutert et al. 2012; Muhlemann et al. 2014; Sailer et al. 2009b; Truninger et al. 2012).

The present study showed that the narrow diameter zirconia abutments exhibited differences in mean strength depending on the type of design and connection. Internal connections of the one-piece zirconia abutments led to slight plastic deformation of the implant-abutment complex whereas in case of externally connected one-piece zirconia abutments fracture occurred prior to any deformation, indicating that this type of zirconia abutment had less mechanical stability. The outcomes of the present study and also previous investigations support this assumption. Moreover, the range between minimum and maximum bending moments within the groups differed. Namely in group T1, 1-piece zirconia abutment with internal implant abutment connection, the range was the largest, compared to those of the other groups. Common mean values are helpful for the clinician to compare various types of zirconia-based reconstructions and relate them to traditional metal-based restorations. Apart from these, outliers have to be carefully considered. The relatively large differences between minimum and maximum bending moments might have a significant influence on the choice for a specific reconstruction in terms of clinical 
indications. In situations with higher occlusal forces, one has to take into account that for some zirconia abutments and specific implant-abutment connections, the observed minimum bending moments might not be sufficient to support the desired reconstruction.

Depending on the design of the abutment and the type of connection, several reasons might explain these relatively large differences. The use of an internal connection without metallic coupling (group 1) provides a one-piece abutment design and, due to a fully industrialized process, the manufacturer can control the quality. The production process of CAD/CAM abutments using a metallic coupling (titanium base) includes a standardized step (milling of the abutment) by the manufacturer but, in addition, a second step with a dental technician preparing the titanium base and cementing the abutment. This step can not be performed under industrialized settings and might explain a higher range of minimum and maximum values for groups 3 and 4 . The process of adhesive cementation is, therefore, critical and involves a series of possible mistakes, in part at least, explaining a higher variation of bending moment values with the two groups.

In implant dentistry, ISO 14801 serves as the only standard requiring $1 \times 10^{6}$ cycles with an upper load limit of $100 \mathrm{~N}$ at $30^{\circ}$ axial loading. It has been previously reported that $2 \times 10^{6}$ cycles correspond to approximately four years of physiological occlusal and masticatory activity (Baldissara et al. 2010; Ozcan \& Jonasch 2016). Nevertheless, a recent systematic review indicated that in all studies fatigue loading tends to decrease the results regardless of the cyclic loading conditions (Coray et al. 2016). In addition, ISO 14801 requires embedding the implants with $3 \mathrm{~mm}$ implant neck exposure prior to loading in order to increase the torque effect that certainly represents a worse case clinical scenario. The results of this study should be verified using mechanically more stable reconstruction materials, and by randomized controlled clinical trials. 


\section{Conclusions}

From this study the following could be concluded:

1- Un-restored narrow diameter two-piece zirconia abutments connected internally to the implants by means of a titanium resin base were significantly more stable than all other tested one- or two-piece zirconia abutments.

2- Un-restored internally connected two-piece zirconia abutments fixed by means of titanium resin base exhibited similar strength as one-piece titanium abutments.

3- The strength of a one-piece titanium abutment was significantly higher then the strength of zirconia abutment with identical configuration.

4- The strength of one-piece internally connected zirconia abutments was significantly higher than the strength of one-piece externally connected zirconia abutments.

5- The two-piece internally connected zirconium abutments including a metallic click-on internal connection exhibited significantly lower strength than the internally connected zirconia abutment fixed by means of a titanium resin base.

6- For all test groups, the fracture strength decreased significantly when restored with the glass-ceramic crowns and differences between different abutment configuration and materials were also reduced. 


\section{Disclosure}

The authors claim to have no financial interest, either directly or indirectly, in the products or information listed in the paper.

\section{Acknowledgments and source of funding}

The present study was supported by a research grant from 3M ESPE, Seefeld, Germany.

Material support from Nobel Biocare, Zurich, Switzerland and Ivoclar Vivadent, Schaan Liechtenstein is also highly appreciated.

\section{Conflict of Interests}

The authors declare that they have no conflict of interests related to this study. 


\section{Captions to the tables and figures:}

\section{Tables}

Table 1. Overview of all results for un-restored abutments.

Table 2. Comparison of mean bending moments of un-restored abutments with $p$ values adjusted for multiple comparisons by Tukey's method.

Table 3. Overview of all results for abutments restored with glass-ceramic crowns.

Table 4. Comparison of mean bending moments of abutments restored with crowns with $p$ values adjusted for multiple comparisons by Tukey's method.

Table 5. Comparisons between abutments with and without crowns.

\section{Figures}

Fig. 1. The dimension of the implant- abutment connection has been changed from regular platform (titanium) to a narrow platform (zirconium). Note that no modification of the outer shape/ dimensions has been performed.

Fig. 2. Schematic drawing of the setup for aging, testing and information on the parameters needed for the calculation for the bending moment in Ncm. (a; midline, b; simulated $3 \mathrm{~mm}$ bone resorption, I; distance from the simulated bone level to the center of load, F; load, 1; implant, 2; acrylic holder, 3; indenter)

Fig. 3 a. Test group 1 (restored and un-restored); top pictures after chewing simulation and lower after testing.

Fig. 3 b. Test group 2 (restored and un-restored); top pictures after chewing simulation and lower after testing.

Fig. 3 c. Test group 3 (restored and un-restored); top pictures after chewing simulation and lower after testing. 
Fig. 3 d. Test group 4 (restored and un-restored); top pictures after chewing simulation and lower after testing.

Fig. 3 e. Control group (restored and un-restored); top pictures after chewing simulation and lower after testing.

Fig 4a. Cross-section test group 1.

Fig 4b. Cross-section test group 1, at higher magnification.

Fig 4c. Cross-section test group 3 ,

Fig 4d. Cross-section test group 3 at higher magnification

Fig 4e. Cross-section test group 4,

Fig 4f. Cross-section test group 4 at higher magnification

Fig 4g. Cross-section control group

Fig 4h. Cross-section control group at higher magnification

Fig. 5. Box plot for mean bending moments for un-restored abutments.

Fig. 6. Box plot for mean bending moments for abutments restored with crowns. 


\section{Tables and Figures}

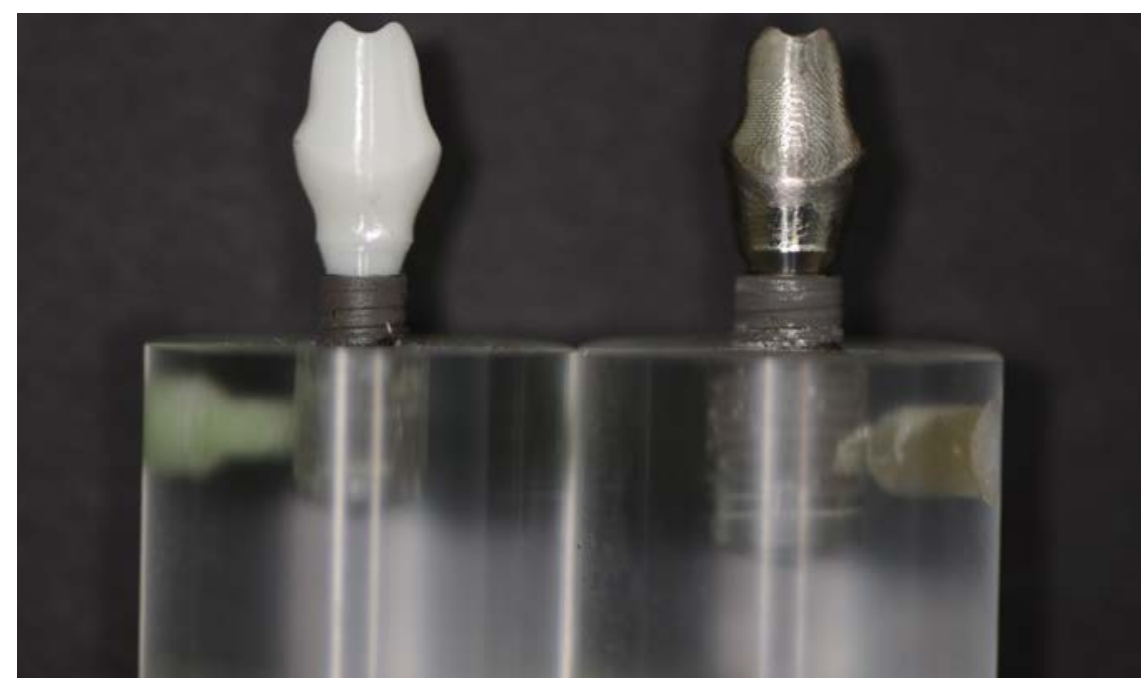

Fig.

1. The dimension of the implant- abutment connection has been changed from regular platform (titanium) to a narrow platform (zirconium). Note that no modification of the outer shape/ dimensions has been performed.

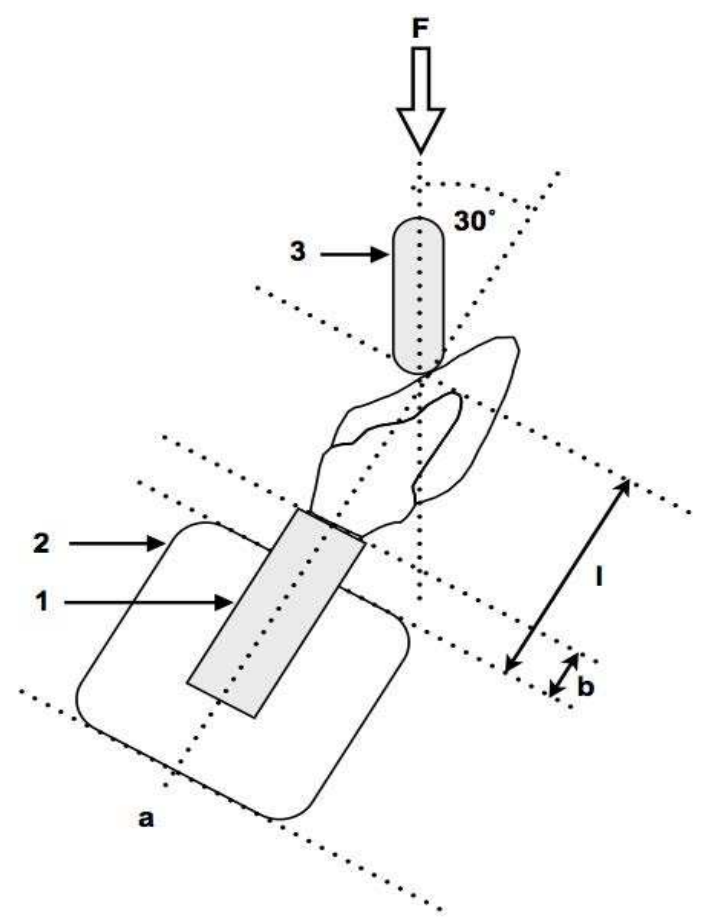

Fig. 2. Schematic drawing of the setup for aging, testing and information on the parameters needed for the calculation for the bending moment in $\mathrm{Ncm}$. (a; midline, b; simulated $3 \mathrm{~mm}$ bone resorption, I; distance from the simulated bone level to the center of load, F; load, 1; implant, 2; acrylic holder, 3; indenter) 


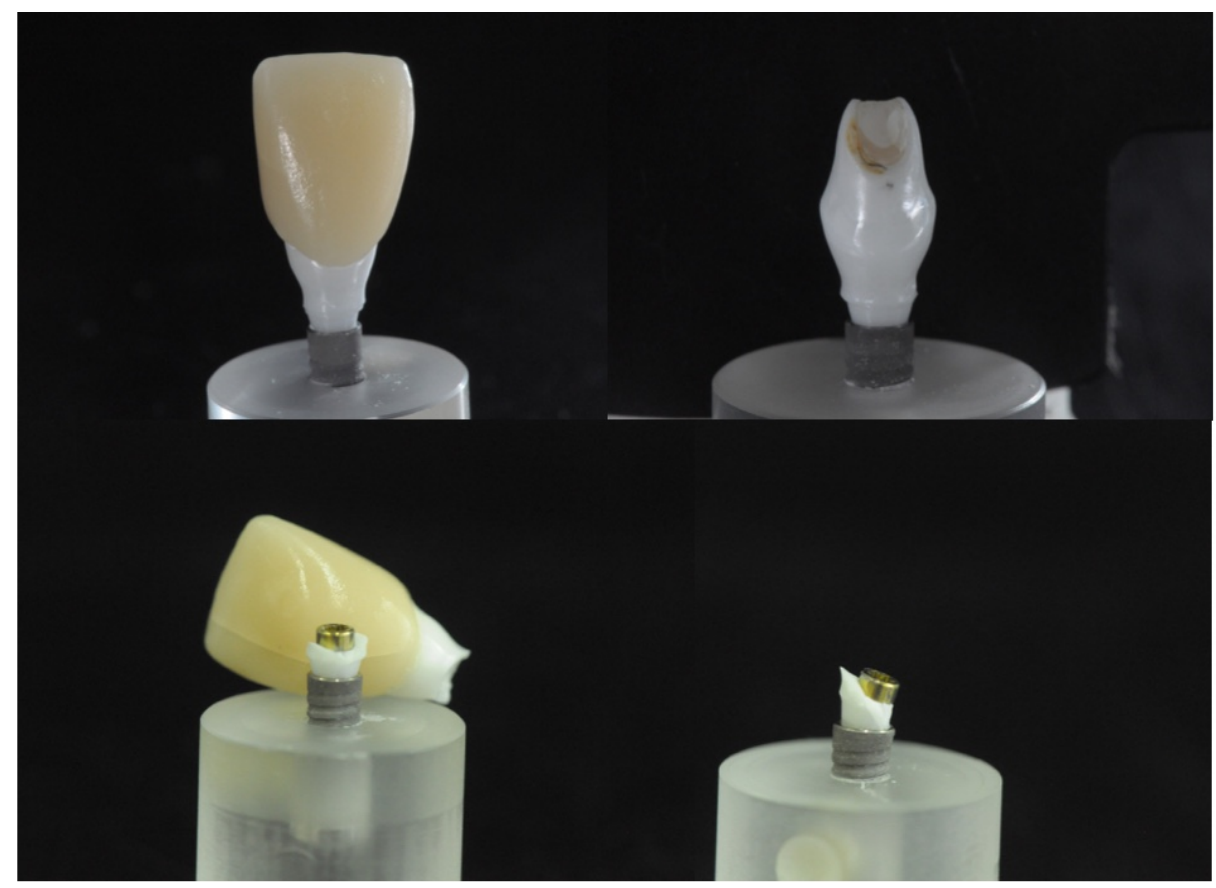

- Test-group 1: 1- piece zirconia abutment with internal implant abutment connection (Cares abutments on Bonelexel NC Roxolid implants, Straumann, Basel, Switzerland).

Fig. $3 a$

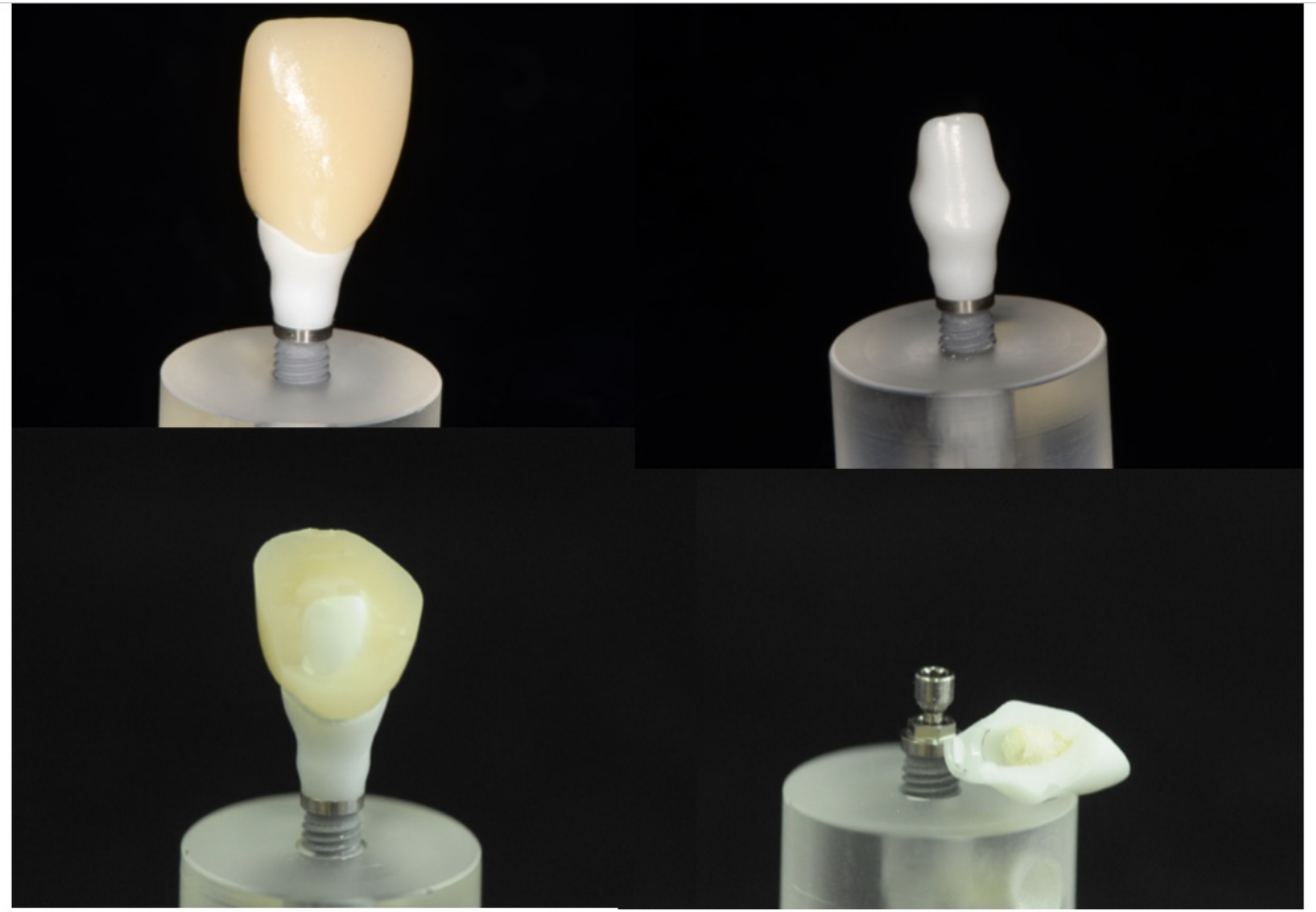

-Test-group 2: 1- piece zirconia abutment with external implant abutment connection (Procerera abutments on Brânemark MK III NP implants, Nobel Biocare, Gothenburg, Sweden). 
Fig. $3 b$

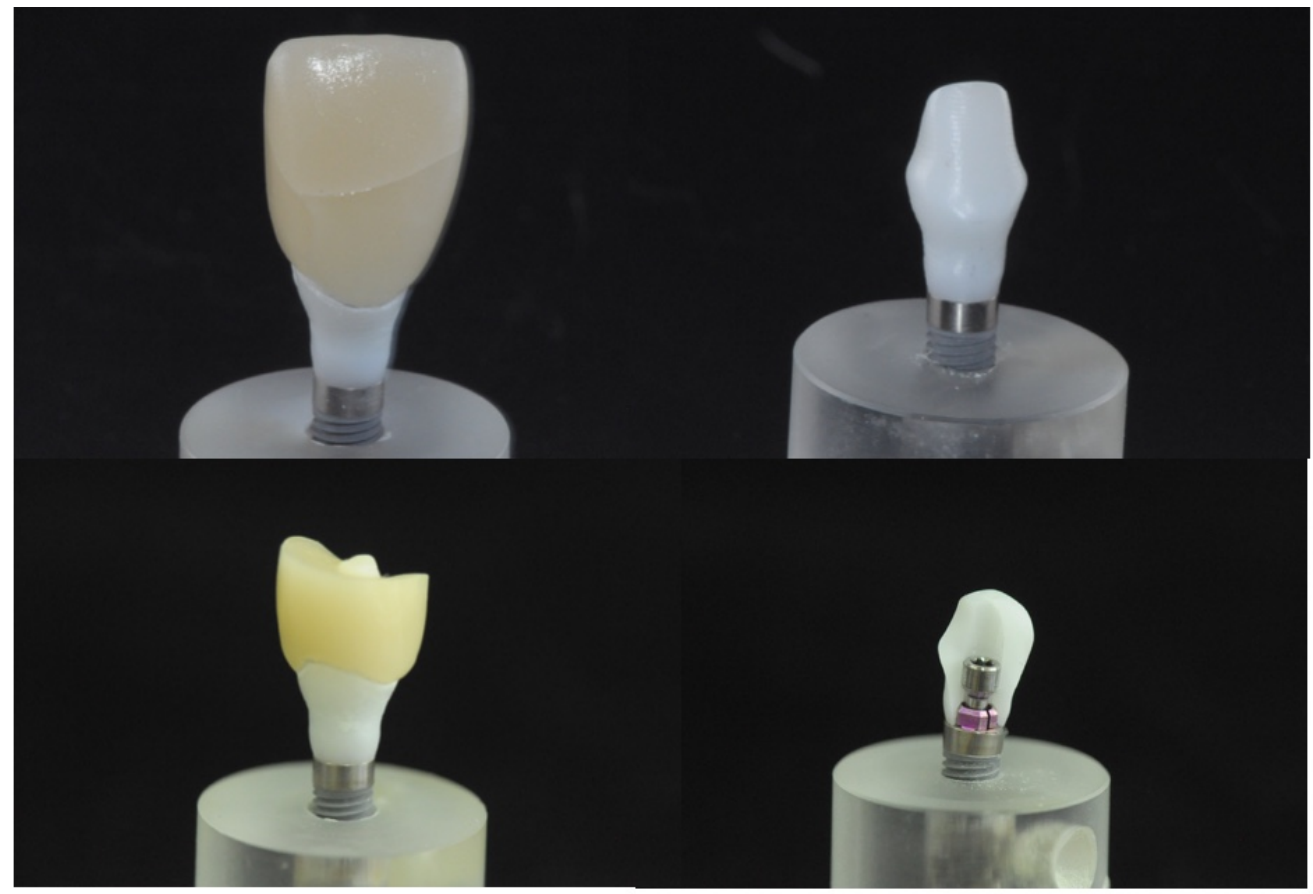

- Test-group 3: 2- piece zirconia abutment with internal implant abutment connection provided by a corresponding secondary metallic coupling (Procera abutments on Replace Select straight NP, Nobel Biocare, Gothenburg, Sweden).

Fig. 3c

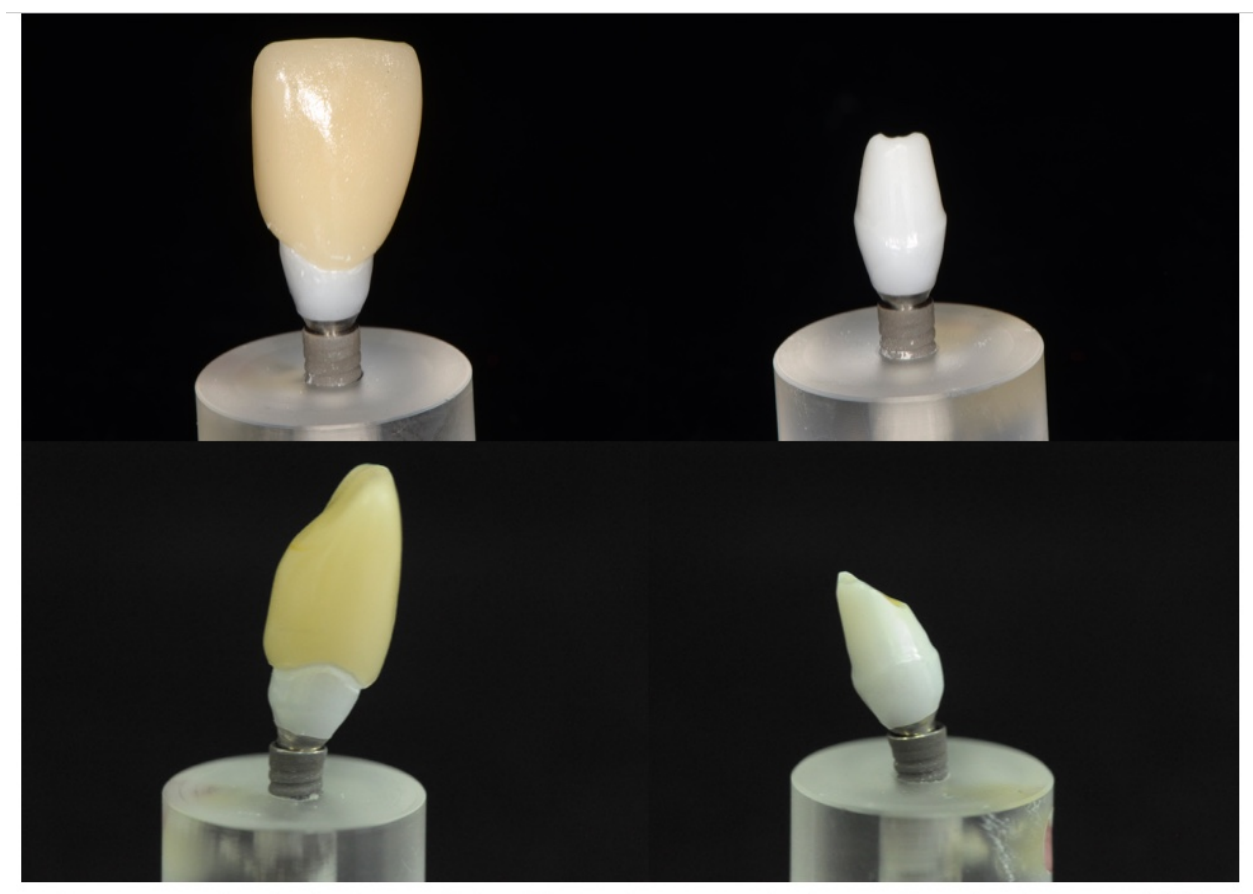

-Test-group 4: 2- piece zirconia abutment with internal implant abutment connection (Lava translucent zirconia abutments (ESPE, Germany), on Bonelevel NC Roxolid implants, Straumann, Basel, Switzerland) provided by an adhesive base (Variobase, Straumann). 
Fig. 3d

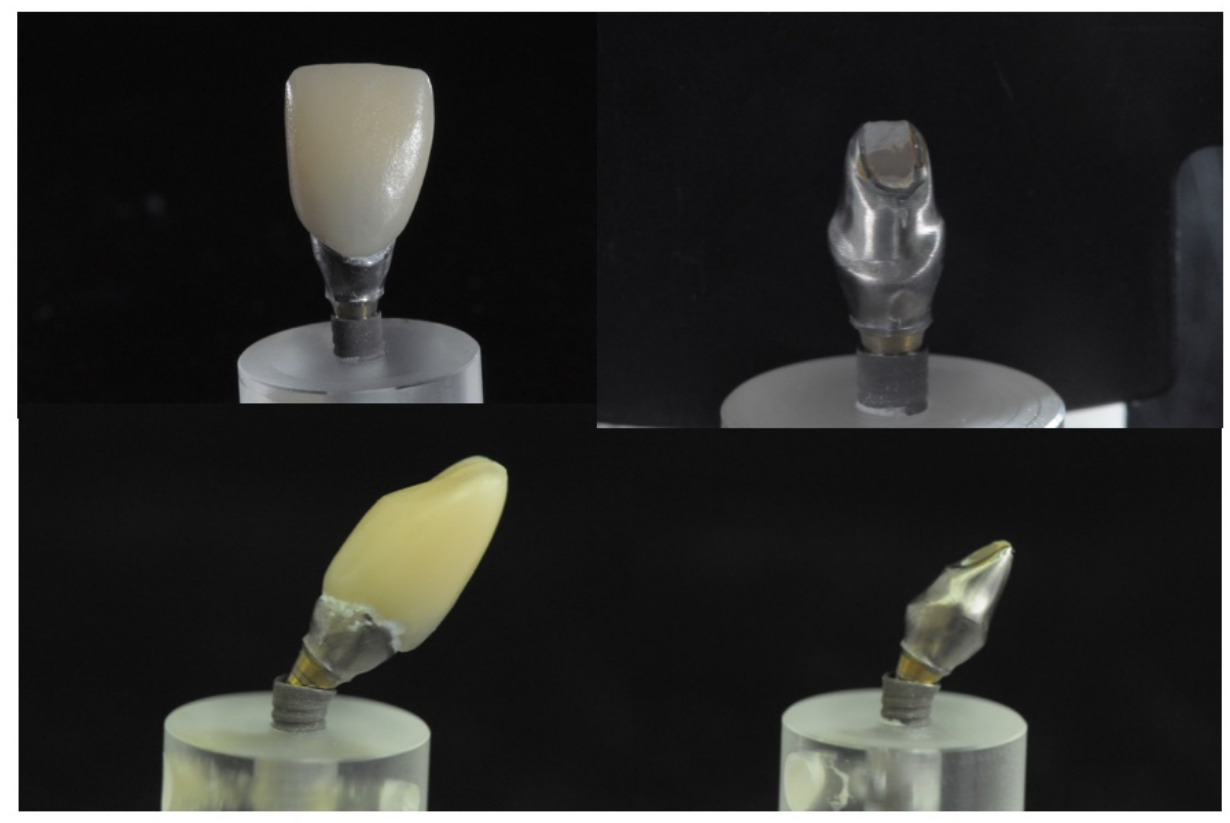

-Control-group: 1- piece titanium abutments with internal implant abutment connection (CARES abutments on Bonelevel NC Roxolid implants, Straumann, Basel, Switzerland).

Fig. 3e 


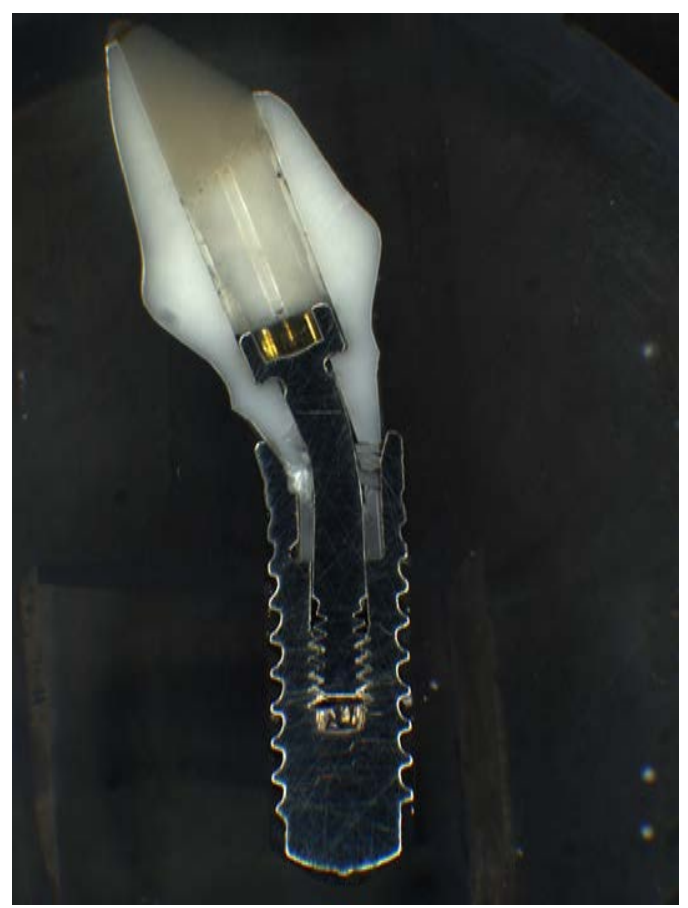

Fig. 4a 


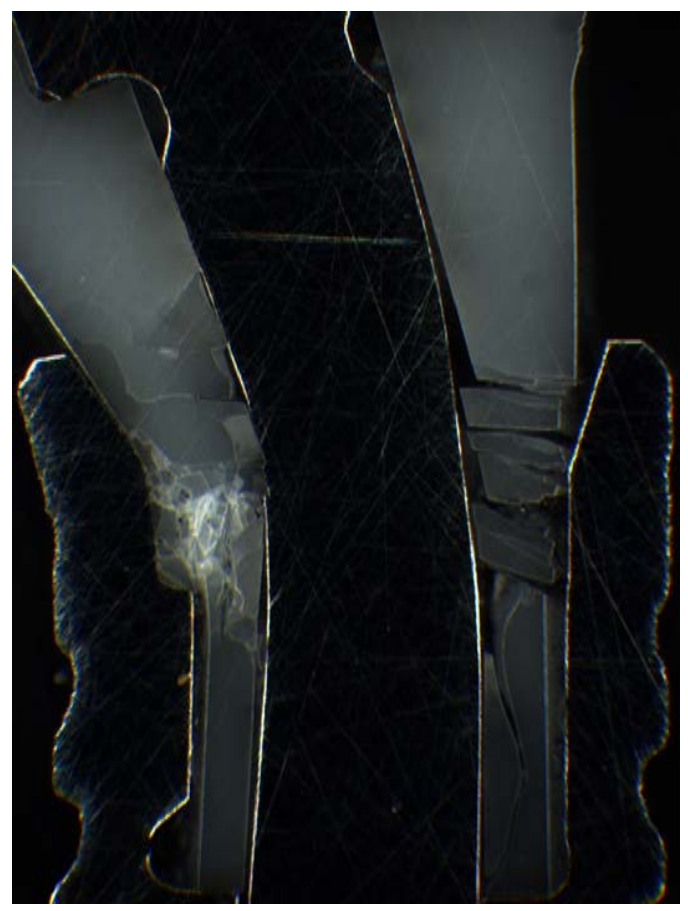

Fig. $4 b$ 


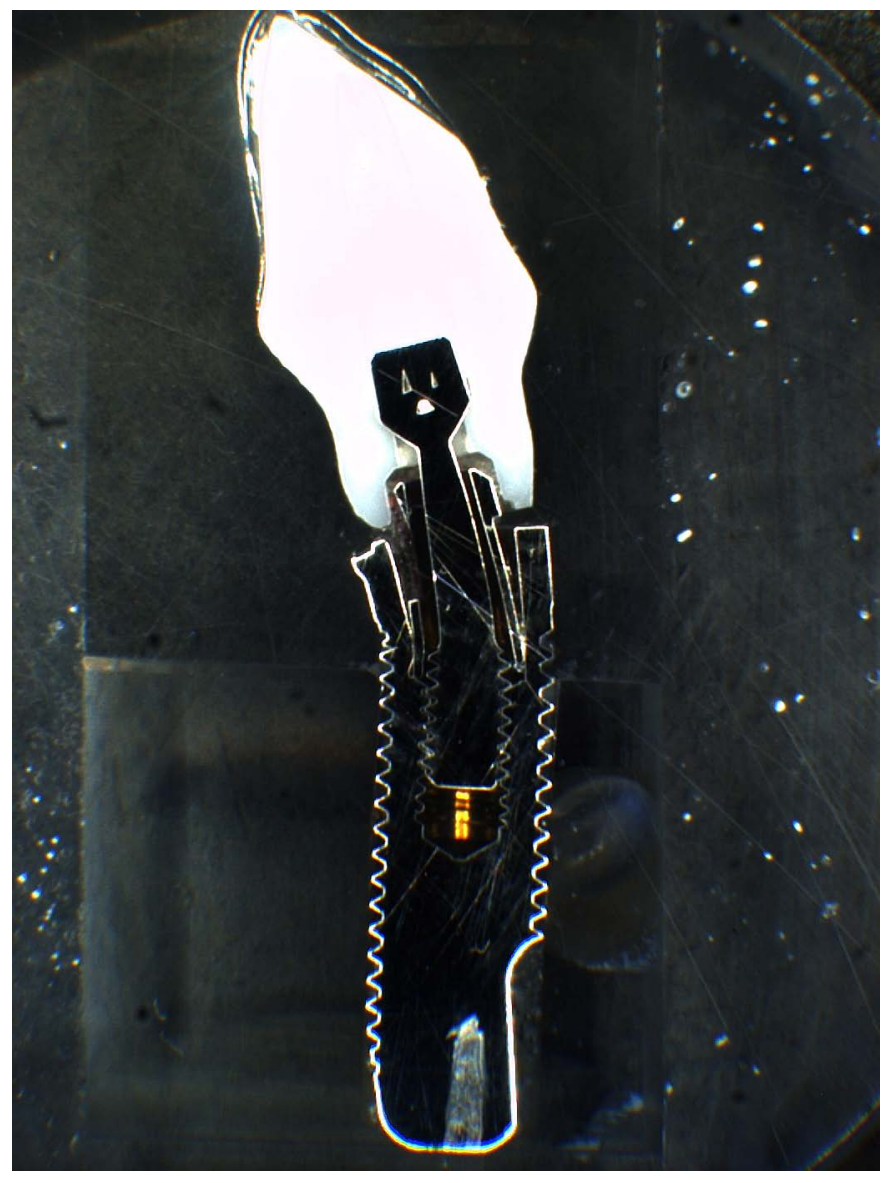

Fig. 4c 


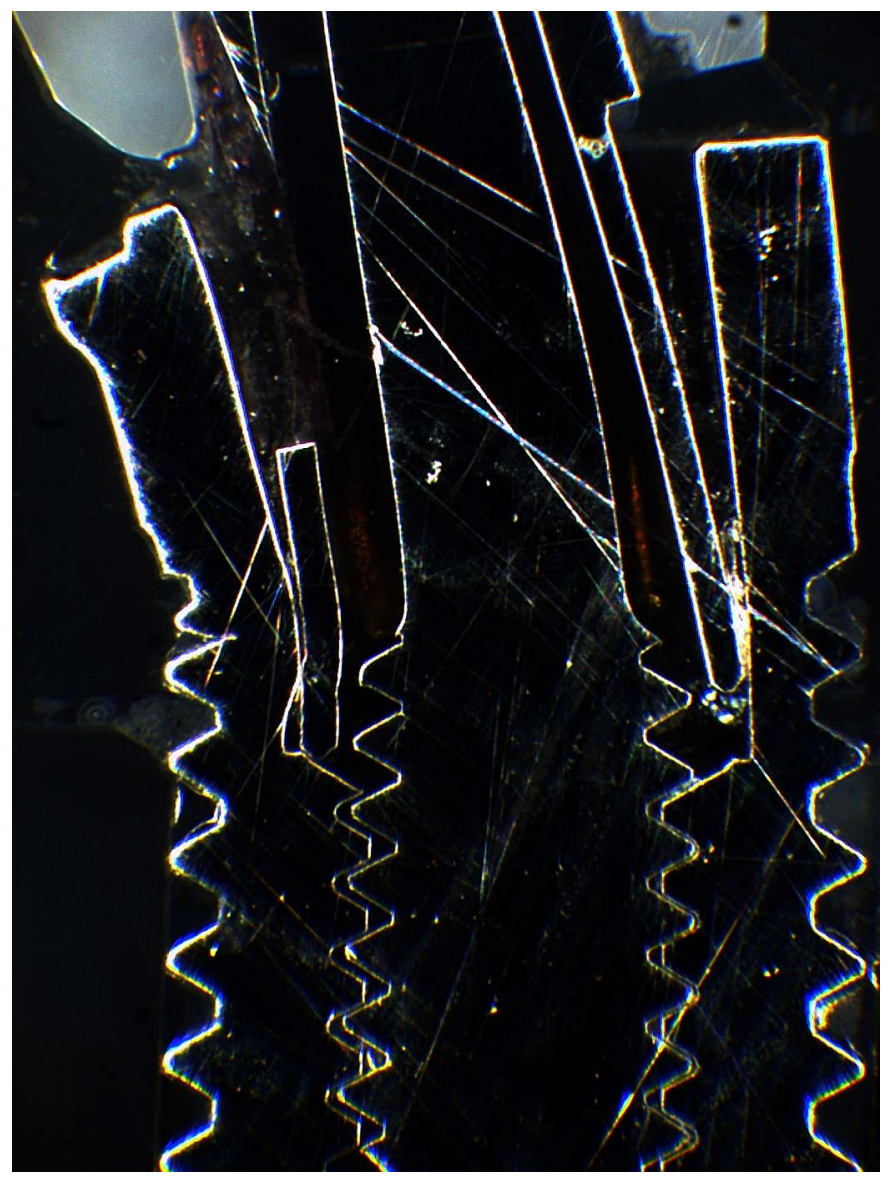

Fig. 4d 


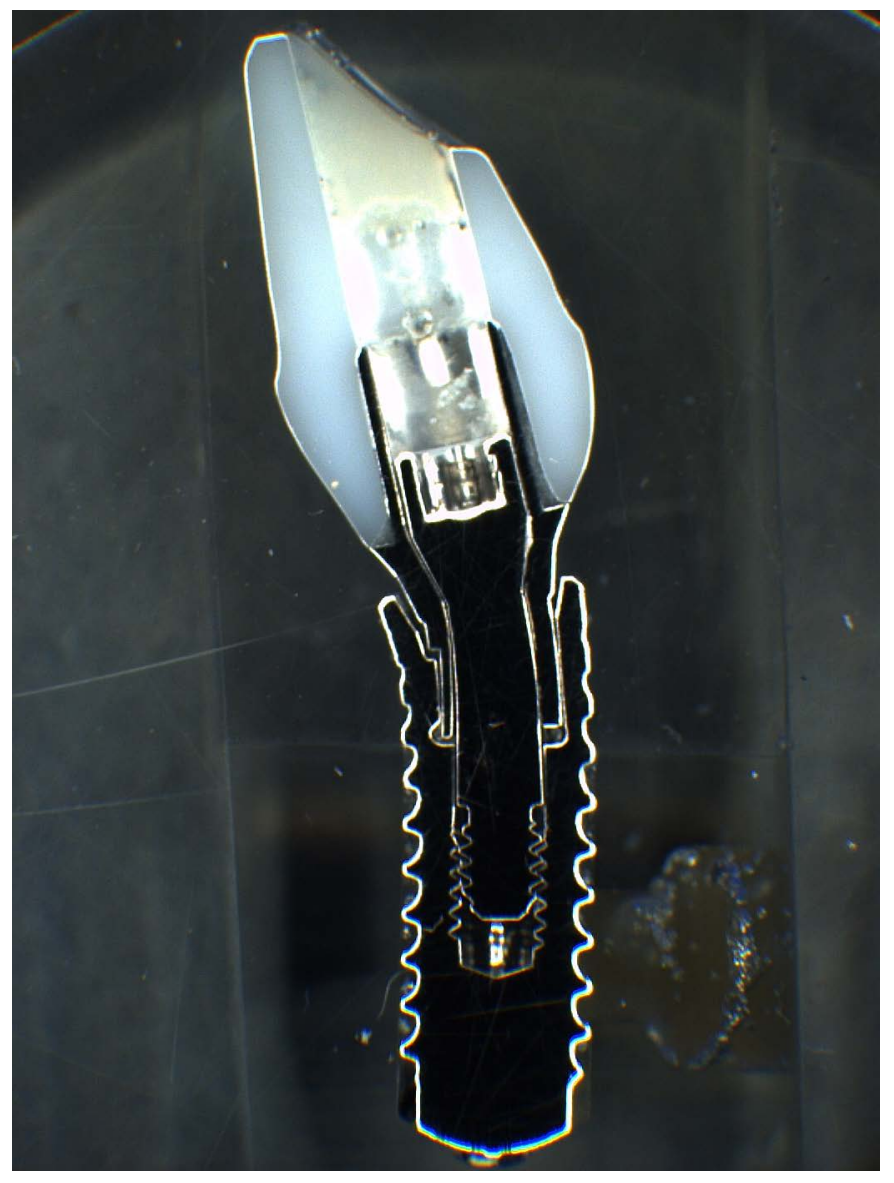

Fig. $4 e$ 


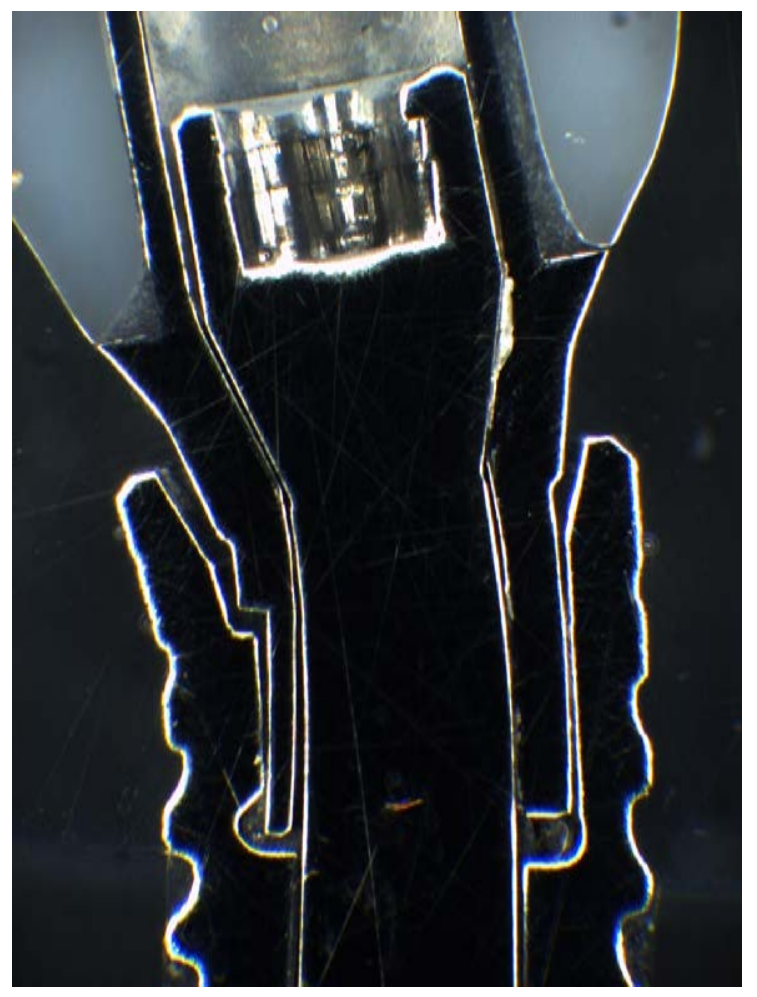

Fig. $4 f$ 


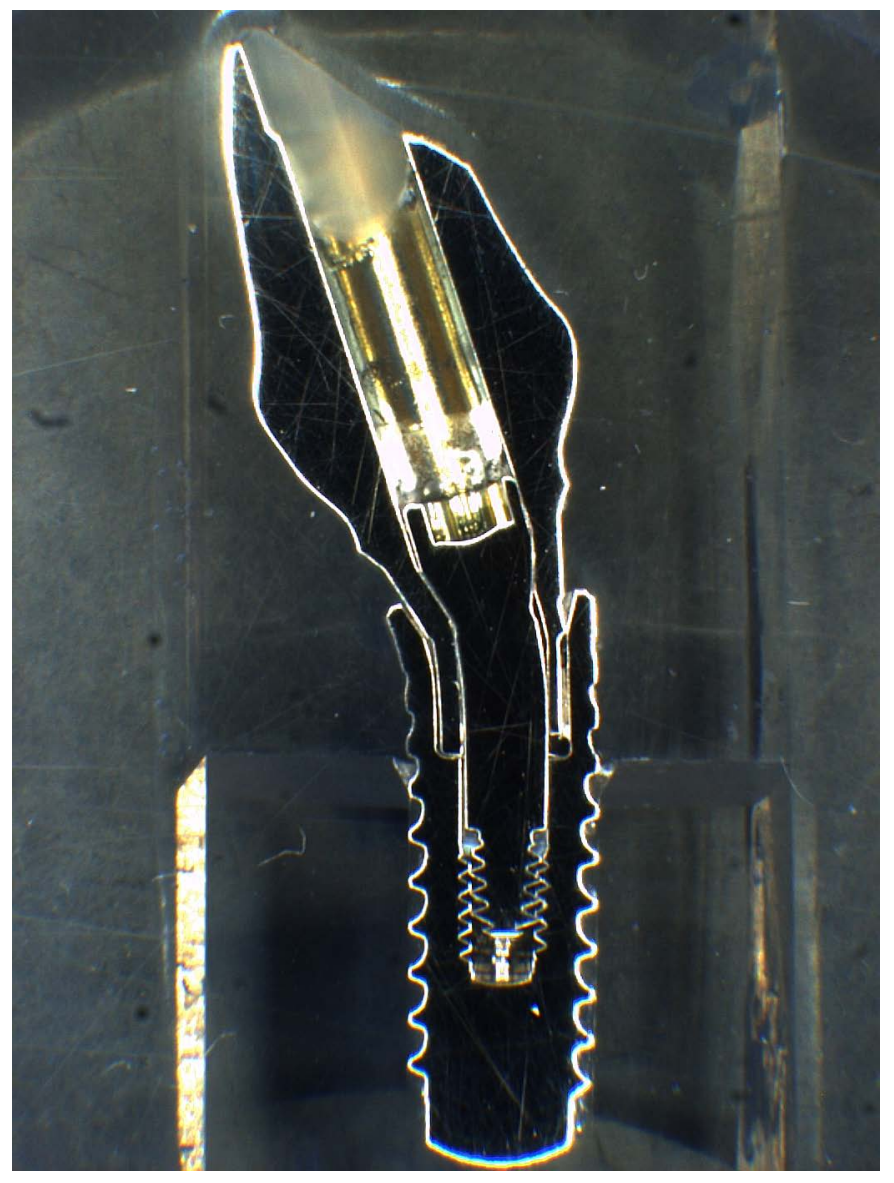

Fig. $4 g$ 


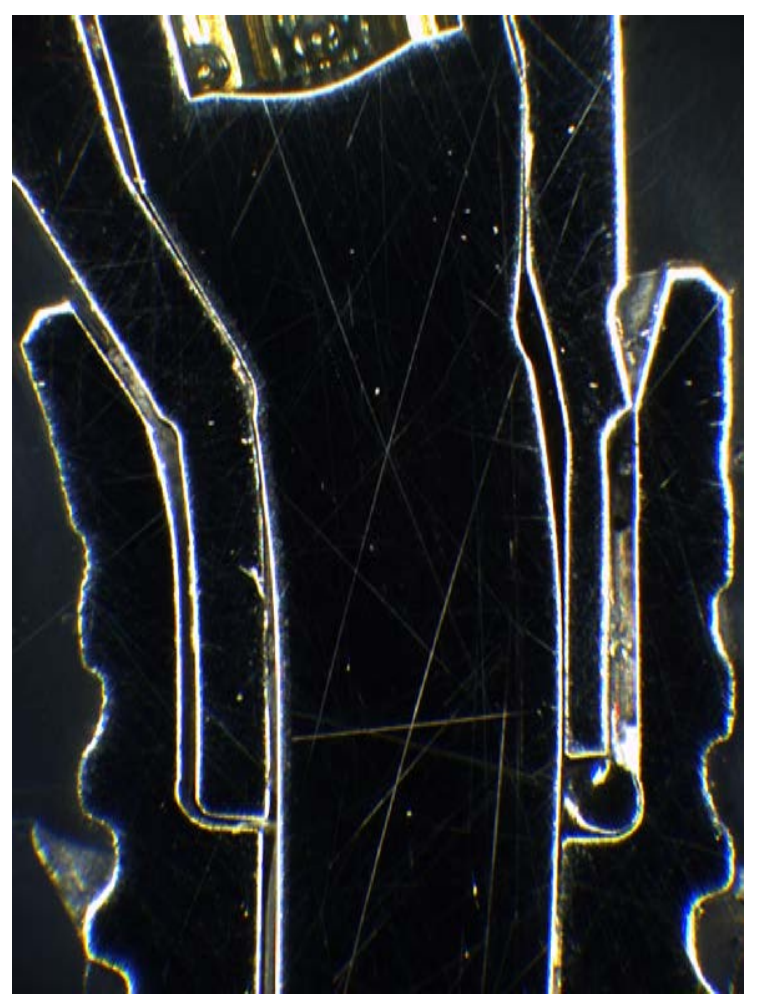

Fig. 4h 


\begin{tabular}{|c|c|c|c|c|c|}
\hline & 1-piece Zir & 1-piece Zir & 2-piece Ti/Zir & 2-piece Ti/Zir & 1-piece Ti \\
\hline & Test group 1 & Test group 2 & Test group 3 & Test group 4 & Control group \\
\hline & $\begin{array}{c}\text { Straumann } \\
\text { Roxolid } \AA 3.3 \mathrm{~mm} \\
\text { Bone level } \\
\text { Cares Zirconia } \\
\text { abutment }\end{array}$ & $\begin{array}{c}\text { Brånemark MK } \\
\text { III }{ }^{\circledR} 3.5 \mathrm{~mm} \text { with } \\
\text { external hex and } \\
\text { Procera }{ }^{\circledR} \text { zirconia } \\
\text { abutment }\end{array}$ & $\begin{array}{c}\text { Nobel Replace } \\
\text { Select }{ }^{\circledR} \text { NP with } \\
\text { Procera }{ }^{\circledR} \text { zirconia } \\
\text { abutment }\end{array}$ & $\begin{array}{c}\text { Straumann } \\
\text { Roxolid } \AA 3.3 \mathrm{~mm} \\
\text { Bone level } \\
\text { Variobase } \AA \\
\text { titanium with } 3 \mathrm{M} \\
\text { ESPE Lava core }\end{array}$ & $\begin{array}{c}\text { Straumann } \\
\text { Roxolid } \AA 3.3 \mathrm{~mm} \\
\text { Bone level } \\
\text { Cares Titanium } \\
\text { abutment }\end{array}$ \\
\hline Number of abutments & 12 & 12 & 12 & 12 & 12 \\
\hline \multicolumn{6}{|c|}{ Findings at the ageing process } \\
\hline $\begin{array}{lr}\begin{array}{l}\text { Fractured or } \\
\text { abutments } \\
\text { ageing process }\end{array} & \text { during } \\
\end{array}$ & 0 & 0 & 0 & 0 & 0 \\
\hline $\begin{array}{l}\text { Abutment loosening } \\
\text { during ageing process }\end{array}$ & 0 & 0 & 0 & 0 & 0 \\
\hline \multicolumn{6}{|c|}{ Findings at the fracture strength test } \\
\hline Initial distortion $(\mathrm{N})$ & $246.0 \pm 77.0$ & $109.5 \pm 73.1$ & $266.4 \pm 80.6$ & $83.7 \pm 21.2$ & $377.6 \pm 125.3$ \\
\hline Maximum force $(\mathrm{N})$ & $501.6 \pm 174.0$ & $362.1 \pm 46.7$ & $427.0 \pm 41.0$ & $883.1 \pm 56.3$ & $651.2 \pm 58.5$ \\
\hline Length of sample (cm) & 1.24 & 1.24 & 1.24 & 1.18 & 1.24 \\
\hline Bending moment $(\mathrm{Ncm})$ & $311.0 \pm 107.9$ & $224.5 \pm 29.0$ & $264.7 \pm 25.4$ & $521.1 \pm 33.2$ & $403.7 \pm 36.3$ \\
\hline Minimum (Ncm) & 205.9 & 171.2 & 219.8 & 477.4 & 362.8 \\
\hline Maximum (Ncm) & 492.3 & 275.2 & 303.4 & 579.9 & 479.0 \\
\hline Abutment fracture & 12 & 12 & 12 & 0 & 0 \\
\hline Internal & 12 & 0 & 0 & 0 & 0 \\
\hline External & 0 & 12 & 12 & 0 & 0 \\
\hline $\begin{array}{l}\text { Abutment screw } \\
\text { fracture }\end{array}$ & 0 & 0 & 0 & 0 & 0 \\
\hline $\begin{array}{l}\text { Abutment screw } \\
\text { loosening (after } \\
\text { deformation) }\end{array}$ & 0 & 11 & 10 & 0 & 0 \\
\hline Deformation & 12 & 7 & 12 & 12 & 12 \\
\hline
\end{tabular}

Table 1. Overview of all results for un-restored abutments. 


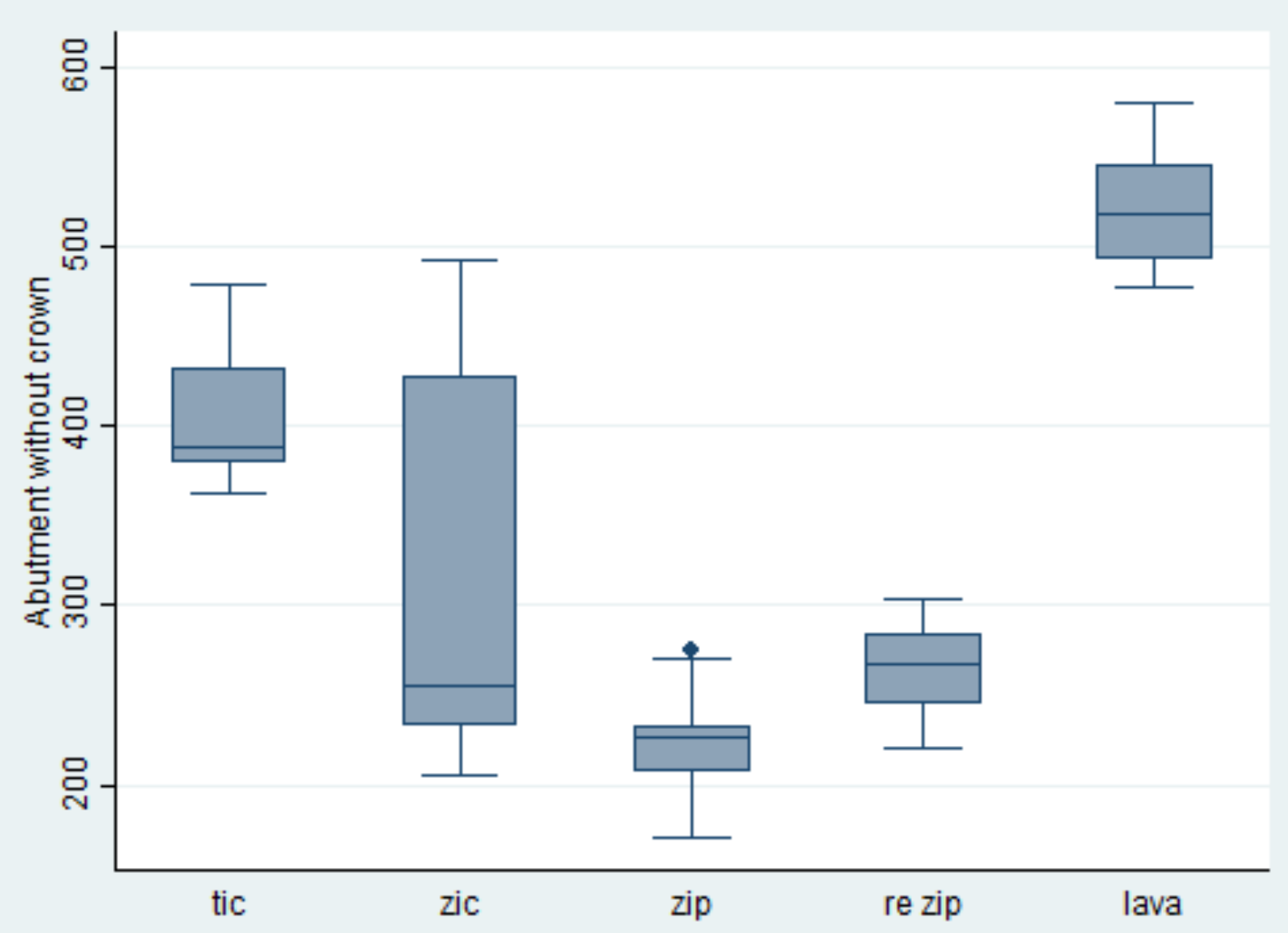

Figure 5. Box plot for mean bending moments for un-restored abutments

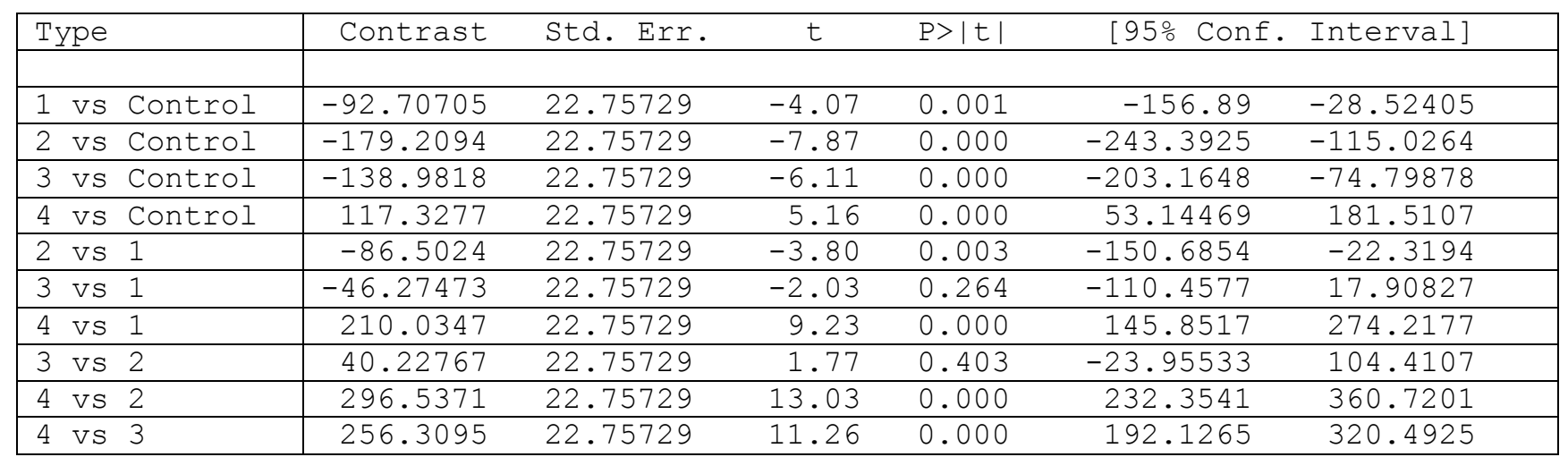

Table 2. Comparison of mean bending moments of un-restored abutments with $\mathrm{p}$ values adjusted for multiple comparisons by Tukey's method. 


\begin{tabular}{|c|c|c|c|c|c|}
\hline & 1-piece Zir & 1-piece Zir & 2-piece Ti/Zir & 2-piece Ti/Zir & 1-piece Ti \\
\hline & Test group 1 & Test group 2 & Test group 3 & Test group 4 & Control group \\
\hline & $\begin{array}{c}\text { Straumann } \\
\text { Roxolid } \AA 3.3 \mathrm{~mm} \\
\text { Bone level } \\
\text { Cares Zirconia } \\
\text { abutment }\end{array}$ & $\begin{array}{c}\text { Brånemark MK } \\
\text { III® } 3.5 \mathrm{~mm} \text { with } \\
\text { external hex and } \\
\text { Procera }{ }^{\circledR} \text { zirconia } \\
\text { abutment }\end{array}$ & $\begin{array}{c}\text { Nobel Replace } \\
\text { Select }{ }^{\circledR} \text { NP with } \\
\text { Procera }{ }^{\circledR} \text { zirconia } \\
\text { abutment }\end{array}$ & $\begin{array}{c}\text { Straumann } \\
\text { Roxolid } \AA 3.3 \mathrm{~mm} \\
\text { Bone level } \\
\text { Variobase }{ }^{\circledR} \\
\text { titanium with } 3 \mathrm{M} \\
\text { ESPE Lava core }\end{array}$ & $\begin{array}{c}\text { Straumann } \\
\text { Roxolid } \AA 3.3 \mathrm{~mm} \\
\text { Bone level } \\
\text { Cares Titanium } \\
\text { abutment }\end{array}$ \\
\hline Number of abutments & 12 & 12 & 12 & 12 & 12 \\
\hline \multicolumn{6}{|c|}{ Findings during the ageing } \\
\hline $\begin{array}{l}\text { Crowns cracked during } \\
\text { ageing process }\end{array}$ & 0 & 2 & 6 & 0 & 2 \\
\hline $\begin{array}{l}\text { Abutment loosening } \\
\text { during ageing process }\end{array}$ & 0 & 0 & 0 & 0 & 0 \\
\hline \multicolumn{6}{|c|}{ Findings during the fracture strength test } \\
\hline Initial distortion $(\mathrm{N})$ & $111.4 \pm 47.9$ & $44.9 \pm 21.8$ & $64.1 \pm 85.5$ & $52.6 \pm 14.4$ & $147.3 \pm 94.6$ \\
\hline Maximum force $(\mathrm{N})$ & $202.2 \pm 58.9$ & $133.4 \pm 60.9$ & $85.5 \pm 108.7$ & $301.6 \pm 90.8$ & $321.0 \pm 181.1$ \\
\hline Length of sample (cm) & 1.88 & 1.88 & 1.88 & 1.84 & 1.88 \\
\hline Bending moment $(\mathrm{Ncm})$ & $190.1 \pm 55.4$ & $125.4 \pm 57.2$ & $80.4 \pm 102.1$ & $277.5 \pm 83.5$ & $301.8 \pm 170.2$ \\
\hline Minimum (Ncm) & 113.9 & 32.7 & 1.8 & 128.2 & 8.6 \\
\hline Maximum (Ncm) & 258.7 & 188.3 & 244.7 & 285.4 & 605.4 \\
\hline $\begin{array}{l}\text { Abutment fracture at } \\
\text { test }\end{array}$ & 11 & 3 & 2 & 1 & 0 \\
\hline Internal & 0 & 0 & 0 & 0 & 0 \\
\hline External & 11 & 3 & 2 & 1 & 0 \\
\hline Crown fracture at test & 3 & 10 & 11 & 5 & 6 \\
\hline Crack & 1 & 1 & 1 & 3 & 2 \\
\hline $\begin{array}{l}\text { Abutment intact after } \\
\text { the test }\end{array}$ & 1 & 9 & 10 & 11 & 12 \\
\hline Complete fracture & 11 & 3 & 0 & 1 & 0 \\
\hline $\begin{array}{l}\text { Abutment screw } \\
\text { fracture }\end{array}$ & 0 & 0 & 0 & 0 & 0 \\
\hline De-bonding & 0 & 0 & 0 & 0 & 0 \\
\hline Deformation & 0 & 0 & 2 & 9 & 6 \\
\hline
\end{tabular}

Table 3. Overview of all results for abutments restored with glass- ceramic crowns. 


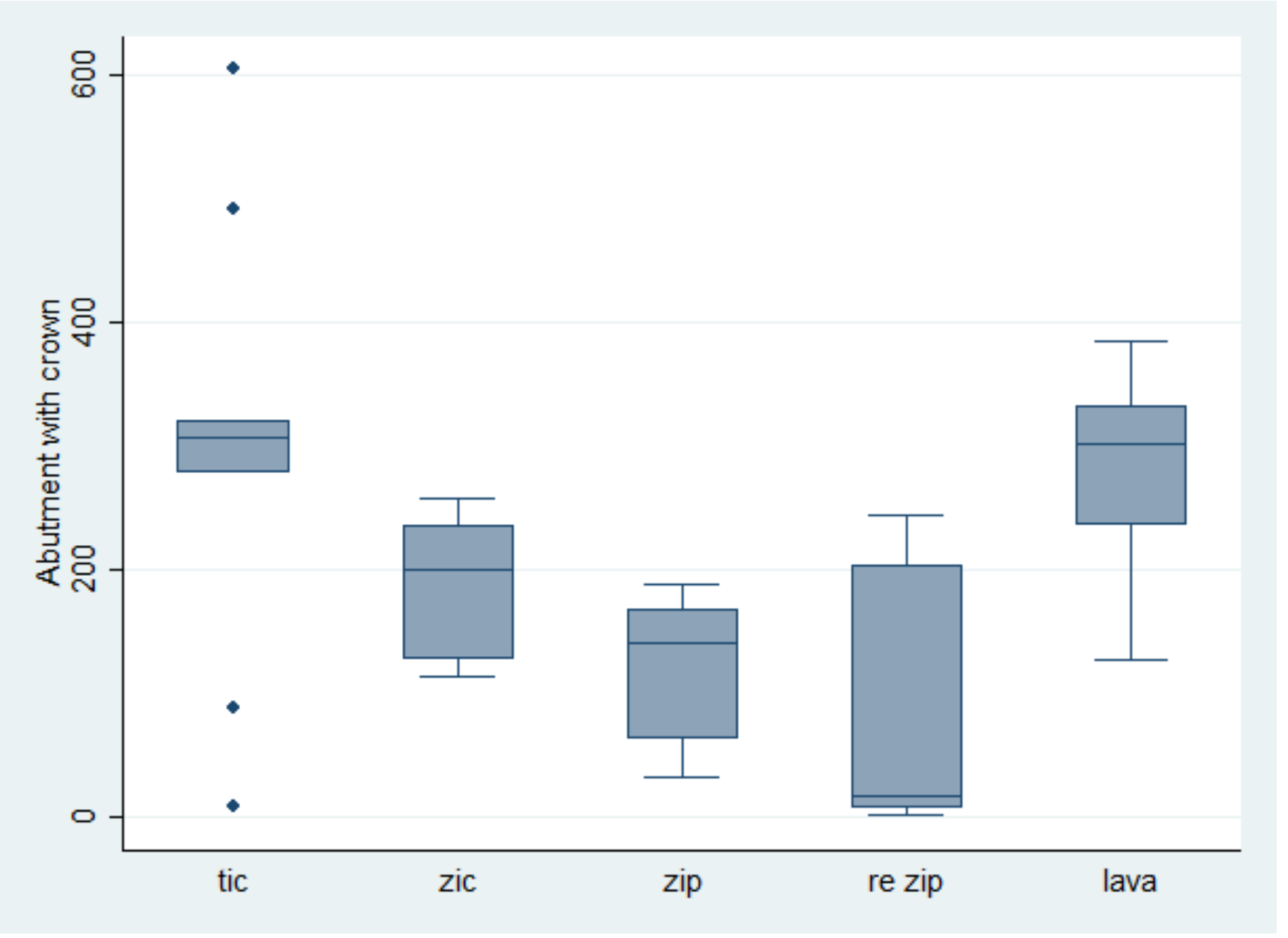

Figure 6. Box plot for mean bending moments for abutments restored with leucite crowns.

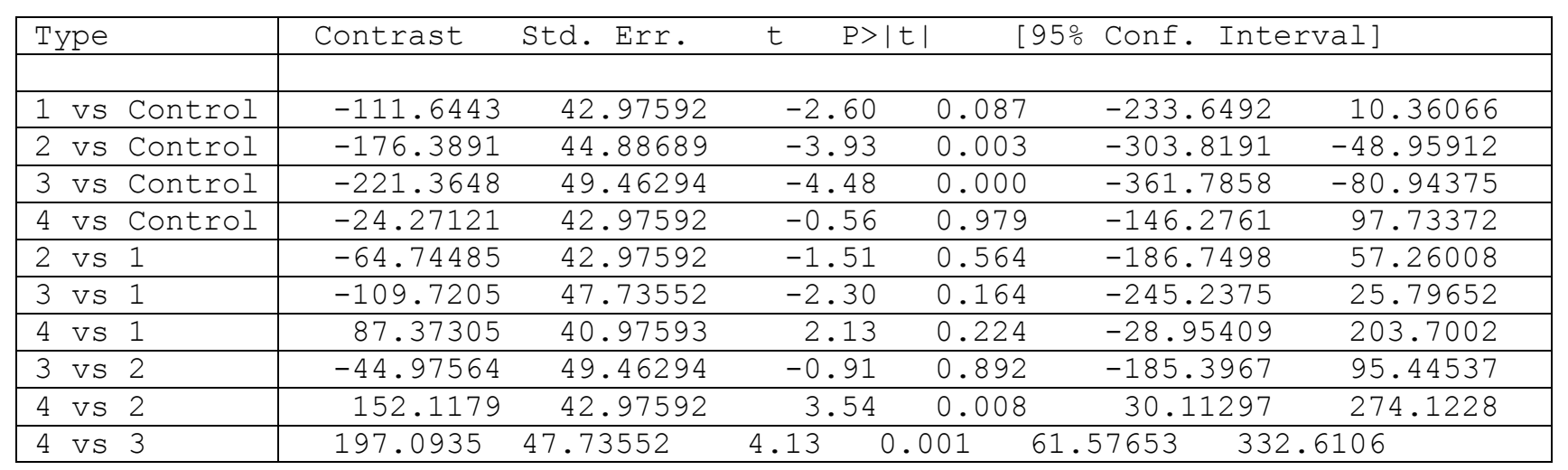

Table 4. Comparison of mean bending moments of abutments restored with crowns with $p$ values adjusted for multiple comparisons by Tukey's method. 


\begin{tabular}{|l|l|c|c|c|}
\hline & & With crown & Without crown & \\
\hline \multicolumn{1}{|c|}{ Group } & Abutment type & $\begin{array}{c}\text { Bending moment } \\
\text { Ncm }\end{array}$ & $\begin{array}{c}\text { Bending moment } \\
\text { Ncm }\end{array}$ & $\mathrm{p}$-value \\
\hline Test 1 & BL Zir & $190.1 \pm 55.4$ & $311.0 \pm 107.9$ & $\mathrm{p}=0.002$ \\
\hline Test 2 & B Zir & $125.4 \pm 57.2$ & $224.5 \pm 29.0$ & $\mathrm{p}<0.00001$ \\
\hline Test 3 & RP Ti/Zir & $80.4 \pm 102.1$ & $264.7 \pm 25.4$ & $\mathrm{p}<0.00001$ \\
\hline Test 4 & BL Ti/Zir & $277.5 \pm 83.5$ & $521.1 \pm 33.2$ & $\mathrm{p}<0.00001$ \\
\hline Control & BL Ti & $301.8 \pm 170.2$ & $403.7 \pm 36.3$ & $\mathrm{p}=0.056$ \\
\hline
\end{tabular}

Table 5 - Comparisons between abutments with and without glass ceramic crowns.

\section{References}

Andersson, B., Odman, P., Lindvall, A. M. \& Lithner, B. (1995) Single-tooth restorations supported by osseointegrated implants: results and experiences from a prospective study after 2 to 3 years. International Journal of Oral and Maxillofacial Implants 10: 702-711. Andersson, B., Taylor, A., Lang, B. R., Scheller, H., Scharer, P., Sorensen, J. A. \& Tarnow, D. (2001) Alumina ceramic implant abutments used for single-tooth replacement: a prospective 1- to 3-year multicenter study. International Journal of Prosthodontics 14: 432-438.

Att, W., Kurun, S., Gerds, T. \& Strub, J. R. (2006) Fracture resistance of single-tooth implant-supported all-ceramic restorations: an in vitro study. Journal of Prosthetic Dentistry 95: 111-116.

Baldissara, P., Ozcan, M., Melilli, D. \& Valandro, L. F. (2010) Effect of cyclic loading on fracture strength and microleakage of a quartz fiber dowel with different adhesive, cement and resin core material combinations. Minerva Stomatologica 59: 407-414.

Coray, R., Zeltner, M. \& Ozcan, M. (2016) Fracture strength of implant abutments after fatigue testing: A systematic review and a meta-analysis. Journal of the mechanical behavior of biomedical materials 62: 333-346.

Glauser, R., Sailer, I., Wohlwend, A., Studer, S., Schibli, M. \& Scharer, P. (2004) Experimental zirconia abutments for implant-supported single-tooth restorations in esthetically demanding regions: 4-year results of a prospective clinical study. International Journal of Prosthodontics 17: 285-290.

Happe, A., Schulte-Mattler, V., Strassert, C., Naumann, M., Stimmelmayr, M., Zoller, J. E. \& Rothamel, D. (2013) In vitro color changes of soft tissues caused by dyed fluorescent zirconia and nondyed, nonfluorescent zirconia in thin mucosa. International Journal of Periodontics and Restorative Dentistry 33: e1-8.

Ioannidis, A., Gallucci, G. O., Jung, R. E., Borzangy, S., Hammerle, C. H. \& Benic, G. I. (2015) Titanium-zirconium narrow-diameter versus titanium regular-diameter implants for anterior and premolar single crowns: 3-year results of a randomized controlled clinical study. Journal of Clinical Periodontology 42: 1060-1070.

Jung, R. E., Holderegger, C., Sailer, I., Khraisat, A., Suter, A. \& Hammerle, C. H. (2008) The effect of all-ceramic and porcelain-fused-to-metal restorations on marginal periimplant soft tissue color: a randomized controlled clinical trial. International Journal of Periodontics and Restorative Dentistry 28: 357-365. 
Jung, R. E., Zembic, A., Pjetursson, B. E., Zwahlen, M. \& Thoma, D. S. (2012) Systematic review of the survival rate and the incidence of biological, technical, and aesthetic complications of single crowns on implants reported in longitudinal studies with a mean follow-up of 5 years. Clinical Oral Implants Research 23 Suppl 6: 2-21.

Kellerhoff, R. K. \& Fischer, J. (2007) In vitro fracture strength and thermal shock resistance of metal-ceramic crowns with cast and machined AuTi frameworks. Journal of Prosthetic Dentistry 97: 209-215.

Khraisat, A., Stegaroiu, R., Nomura, S. \& Miyakawa, O. (2002) Fatigue resistance of two implant/abutment joint designs. Journal of Prosthetic Dentistry 88: 604-610.

Leutert, C. R., Stawarczyk, B., Truninger, T. C., Hammerle, C. H. \& Sailer, I. (2012) Bending moments and types of failure of zirconia and titanium abutments with internal implant-abutment connections: a laboratory study. International Journal of Oral and Maxillofacial Implants 27: 505-512.

McGlumphy, E. A., Robinson, D. M. \& Mendel, D. A. (1992) Implant superstructures: a comparison of ultimate failure force. International Journal of Oral and Maxillofacial Implants 7: 35-39.

Mollersten, L., Lockowandt, P. \& Linden, L. A. (1997) Comparison of strength and failure mode of seven implant systems: an in vitro test. Journal of Prosthetic Dentistry 78: 582591.

Moraguez, O., Vailati, F., Grutter, L., Sailer, I. \& Belser, U. C. (2016) Four-unit fixed dental prostheses replacing the maxillary incisors supported by two narrow-diameter implants a five-year case series. Clinical Oral Implants Research.

Muhlemann, S., Truninger, T. C., Stawarczyk, B., Hammerle, C. H. \& Sailer, I. (2014) Bending moments of zirconia and titanium implant abutments supporting all-ceramic crowns after aging. Clinical Oral Implants Research 25: 74-81.

Norton, M. R. (1997) An in vitro evaluation of the strength of an internal conical interface compared to a butt joint interface in implant design. Clinical Oral Implants Research 8: 290-298.

Ozcan, M. \& Jonasch, M. (2016) Effect of Cyclic Fatigue Tests on Aging and Their Translational Implications for Survival of All-Ceramic Tooth-Borne Single Crowns and Fixed Dental Prostheses. Journal of Prosthodontics.

Prestipino, V. \& Ingber, A. (1993a) Esthetic high-strength implant abutments. Part I. Journal of Esthetic Dentistry 5: 29-36.

Prestipino, V. \& Ingber, A. (1993b) Esthetic high-strength implant abutments. Part II. Journal of Esthetic Dentistry 5: 63-68.

Sailer, I., Philipp, A., Zembic, A., Pjetursson, B. E., Hammerle, C. H. \& Zwahlen, M. (2009a) A systematic review of the performance of ceramic and metal implant abutments supporting fixed implant reconstructions. Clinical Oral Implants Research 20 Suppl 4: 431.

Sailer, I., Sailer, T., Stawarczyk, B., Jung, R. E. \& Hammerle, C. H. (2009b) In vitro study of the influence of the type of connection on the fracture load of zirconia abutments with internal and external implant-abutment connections. International Journal of Oral and Maxillofacial Implants 24: 850-858.

Thoma, D. S., Jones, A. A., Dard, M., Grize, L., Obrecht, M. \& Cochran, D. L. (2011) Tissue integration of a new titanium-zirconium dental implant: a comparative histologic and radiographic study in the canine. Journal of Periodontology 82: 1453-1461.

Truninger, T. C., Stawarczyk, B., Leutert, C. R., Sailer, T. R., Hammerle, C. H. \& Sailer, I. (2012) Bending moments of zirconia and titanium abutments with internal and external implant-abutment connections after aging and chewing simulation. Clinical Oral Implants Research 23: 12-18. 
Yildirim, M., Fischer, H., Marx, R. \& Edelhoff, D. (2003) In vivo fracture resistance of implant-supported all-ceramic restorations. Journal of Prosthetic Dentistry 90: 325-331. Zembic, A., Bosch, A., Jung, R. E., Hammerle, C. H. \& Sailer, I. (2013) Five-year results of a randomized controlled clinical trial comparing zirconia and titanium abutments supporting single-implant crowns in canine and posterior regions. Clinical Oral Implants Research 24: 384-390. 